Federal Reserve Bank of New York

Staff Reports

\title{
The Sensitivity of Housing \\ Demand to Financing Conditions: \\ Evidence from a Survey
}

\author{
Andreas Fuster \\ Basit Zafar \\ Staff Report No. 702 \\ November 2014 \\ Revised August 2015
}

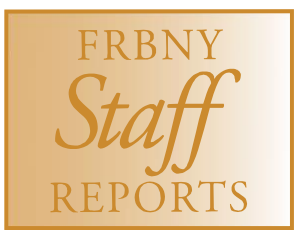

This paper presents preliminary findings and is being distributed to economists and other interested readers solely to stimulate discussion and elicit comments. The views expressed in this paper are those of the authors and do not necessarily reflect the position of the Federal Reserve Bank of New York or the Federal Reserve System. Any errors or omissions are the responsibility of the authors. 


\title{
The Sensitivity of Housing Demand to Financing Conditions: Evidence from a Survey
} Andreas Fuster and Basit Zafar

Federal Reserve Bank of New York Staff Reports, no. 702

November 2014; revised August 2015

JEL classification: E44, G21, R21

\begin{abstract}
The sensitivity of housing demand to mortgage rates and available leverage is key to understanding the effect of monetary and macroprudential policies on the housing market. However, since there is generally no exogenous variation in these variables that is independent of confounding factors (such as economic conditions or household characteristics), it is difficult to cleanly estimate these sensitivities empirically. We circumvent these issues by designing a strategic survey in which respondents are asked for their willingness to pay (WTP) for a home comparable to their current one, under different financing scenarios. We vary mortgage rates, down payment constraints, and non-housing wealth. We find that a relaxation of down payment constraints, or an exogenous increase in non-housing wealth, has large effects on WTP, especially for relatively poorer and more credit-constrained borrowers. On the other hand, changing the mortgage rate by 2 percentage points only changes WTP by about 5 percent on average. These findings have implications for theoretical models of house price determination, as well as for policy.
\end{abstract}

Key words: housing demand, mortgage rates, down payment requirements, user cost model, household survey

Fuster and Zafar: Federal Reserve Bank of New York (e-mail: andreas.fuster@ny.frb.org, basit.zafar@ny.frb.org). The authors are grateful to Anthony DeFusco, Edward Glaeser, Andrew Haughwout, Brian Melzer, Andrew Paciorek, Monika Piazzesi, Stuart Rosenthal, Martin Schneider, Andrea Tambalotti, Joseph Tracy, Stijn Van Nieuwerburgh, Jeff Zabel, and seminar participants at the Federal Reserve Bank of New York, the Swiss National Bank, the Central Bank of Chile, and the Fall 2014 Housing-Urban-Labor-Macro (HULM) conference at the Federal Reserve Bank of Chicago for helpful comments and discussions. Matt Cocci and Karen Shen provided excellent research assistance. The views expressed in this paper are those of the authors and do not necessarily reflect the position of the Federal Reserve Bank of New York or the Federal Reserve System. 


\section{Introduction}

Booms and busts in house prices are among the most important drivers of broader economic cycles. Most recently, a house price boom in the US and many other countries preceded the Great Recession, which was associated with a rapid drop in house prices and a rise in mortgage defaults. There is still substantial disagreement among policymakers and academics as to what drove the housing boom in the first place. Many argue that the housing bubble was inflated by low interest rates due to loose monetary policy (e.g., Taylor, 2009) or a global savings glut (Bernanke, 2005), while others emphasize a reduction in down payment requirements as a primary driver of the boom (e.g., Favilukis, Ludvigson, and Van Nieuwerburgh, 2013). However, a third view is that neither of these factors can realistically explain the extent of the boom, highlighting the potential role of overly optimistic expectations about future price gains in driving rapid house price appreciation (Glaeser, Gottlieb, and Gyourko, 2013). Understanding the relative importance of these factors is important not only to understand the past, but also to shape monetary and financial stability policies of the future. ${ }^{1}$

At the heart of the disagreement about the importance of financing conditions (interest rates; down payment and other constraints) is the difficulty of estimating their effects empirically. The most common approach employed in existing research (reviewed in more detail in Section 2) is time-series analysis at the macro level. This approach, usually executed using vector autoregression or panel data techniques, has the advantage of capturing general equilibrium effects, but requires identification assumptions that are difficult to test, and results will often be sensitive to the set of explanatory variables that is employed. An appealing alternative is to use variation in financing conditions in the cross-section, but only few studies have been able to exploit exogenous variation in conditions to identify their effect. As a result, researchers and policymakers still primarily rely on calibrated "user cost" models to gauge how strongly house prices should react to changes in financing conditions (see Svensson, 2013, for a recent example).

The contribution of this paper is to use a "strategic survey" (a term coined by Ameriks et al., 2011) to gauge the sensitivity of housing demand to mortgage rates, down payment constraints, and an exogenous shock in non-housing wealth. This approach allows us to cleanly identify the average effects of these variables, and also to investigate heterogeneity of the effects across households. As part of the Federal Reserve Bank of New York's Survey of Consumer Expectations, we ask (online)

\footnotetext{
${ }^{1}$ In a recent discussion of these issues, Yellen (2014) argues that macroprudential policies are generally better suited than traditional monetary policy to prevent financial turmoil from excessive asset price movements.
} 
survey respondents to assume they are to move today to a town/city similar to their current one, and ask how much they would be willing and able to pay for a home similar to the one they currently live in, under four different scenarios. ${ }^{2}$ In the first scenario, all respondents are told they would have to make a $20 \%$ down payment, but half the respondents face a mortgage rate of $4.5 \%$ while the others face a rate of $6.5 \%$. This first scenario thus allows us to estimate the importance of mortgage rates by comparing across respondents. We also use it to study the importance of many other observable variables on respondents' willingness to pay (WTP), such as income, savings/debt or credit scores, as well as expectations about home price growth.

In a second scenario, we keep each respondent's mortgage rate unchanged, but allow them to freely choose their down payment, with the restriction that it needs to be at least $5 \%$ of the price they are willing to pay. This allows us to examine the sensitivity of WTP to down payment constraints. We also study heterogeneity in the down payment fraction chosen by our respondents. In the third scenario, we switch respondents' mortgage rates (from $6.5 \%$ to $4.5 \%$, or vice-versa), providing us with a within-respondent estimate of the sensitivity of WTP and down payments to rates. In the fourth and final scenario, our respondents are asked to assume that they just inherited $\$ 100,000$ in cash, allowing us to study the effect of a (large) non-housing wealth shock on WTP and financing.

Our main findings are the following: (1) our respondents' WTPs are not very sensitive to a change in the mortgage rate at which they can finance their (hypothetical) home. Both between and within respondents, we find that average WTP is about $5 \%$ lower when the mortgage rate is $6.5 \%$ instead of $4.5 \%$. (2) The decrease in the required down payment fraction from $20 \%$ to $5 \%$ has much larger effects on WTP-on average, WTP increases by about $15 \%$, though the increase is much larger (around 40\%) for current renters, who tend to choose low down payments. (3) The non-housing wealth shock similarly has large effects-it increases average WTP by about 10\% and down payment fractions by about 20 percentage points, again with larger effects for renters.

We compare our results to the predictions of a standard user cost model calibrated using our survey parameters, as well as to existing empirical estimates of these sensitivities. Our estimated interest rate sensitivity is roughly in line with existing empirical studies, but lower than what a user cost model would predict, suggesting that this widely used model may overstate the sensitivity of house prices to changes in rates. For the sensitivity of WTP to a reduction in the down payment requirement, the model prediction is less sharp, since it strongly depends on a respondent's assumed

\footnotetext{
${ }^{2}$ About three-quarters of our respondents are current homeowners; they are asked to assume that they would first sell their current home and pay off their current mortgage debt before buying their new home. Also, we provide respondents with a calculator that shows effective monthly payments for different purchase prices and down payments, taking into account other costs of homeownership (such as property taxes) and the tax deductibility of mortgage interest payments.
} 
effective discount rate (or shadow cost of funds). Reconciling the strong sensitivity of some of our respondents with the theoretical prediction requires very high effective discount rates (on the order of $20 \%$ /year or higher). We show that it is primarily the less wealthy respondents (particularly renters) that strongly increase their WTP in response to a lower required down payment, consistent with many of them being severely liquidity-constrained.

Our finding that a lowering of down payment requirements has the largest effects on less wealthy respondents' WTP aligns well with the findings of Landvoigt et al. (2015), who study capital gains in the San Diego area during the housing boom and find that these gains were substantially larger at the low end of the market; they then build a quantitative model that explains this with increased availability of credit. A key takeaway from such analyses of heterogeneity is that the effect of a change in down payment requirements on housing demand strongly depends on households' financial situation. For instance, a loosening of down payment requirements will have little effect on the WTP for a new home of current owners with substantial equity, or of renters with substantial liquid savings. The results also imply that macroprudential measures such as a loan-to-value (LTV) cap may predominantly affect the lower end of the housing market, and that the effect on house prices will depend on the state of the economy and other asset markets.

The rich data we collect also includes measures of respondents' subjective expectations of local home price growth, allowing us to test whether heterogeneity in expectations explains some of the dispersion in WTP. We find only a limited role of expectations, although they are significantly correlated with respondents' self-assessed value of their current home, even after controlling for all other observable characteristics.

Our survey-based empirical strategy has several advantages over more common approaches. In particular, it provides clean exogenous variation (both in the cross-section and within-individual) that is otherwise not available in real-world observational data. However, there are some obvious limitations to our stylized approach. Perhaps most importantly, our exercise is partial equilibrium in nature: in our setting, mortgage rates are independent of individuals' effective discount rates, while in reality, changes in the term structure of interest rates presumably affect both (though the precise extent is unclear). Similarly, in reality, changes in housing demand may be partly offset by changes in supply. In addition, potential homebuyers may adjust the size or quality of the home they are looking to buy when financing conditions change whereas we ask them to consider the same home in all scenarios. While these factors imply that our estimates do not directly correspond to predicted effects of financing conditions on equilibrium house prices, they can inform and disci- 
pline general equilibrium models in which different channels can be evaluated separately. ${ }^{3}$

Another concern is that, while the majority of our respondents appear to put considerable thought in their answers (for instance, $78 \%$ use the provided calculator in all questions), in the real world they would presumably deliberate more intensely and perhaps seek outside advice before making such important decisions. However, the main worry is that this adds noise, not that it necessarily biases our analysis. In fact, work in other fields (such as marketing, transportation research or public good valuation) has compared hypothetical choices elicited through surveys with actual decisions, and found that the two produce similar outcome distributions and comparable utility parameters (e.g., Hensher and Bradley, 1993). Furthermore, existing evidence indicates that stated choice also relates strongly to subsequent actual choice (e.g., Delavande and Manski, 2010).

\section{Theoretical framework and related literature}

In this section, we first review the user cost framework that is commonly used to predict how house prices react to financing conditions, and then review the related empirical literature.

The basic user cost model (Hendershott and Slemrod, 1983; Poterba, 1984) is built around the simple no-arbitrage assumption that in equilibrium, the net present costs of renting and owning should be equalized. Using the assumptions and notation of Glaeser et al. (2013), this leads to the following equilibrium rent-to-price $(R / P)$ ratio:

$$
\frac{R}{P}=\theta \rho+(1-\theta)(1-\varphi) r+\tau-g+g(1-\theta)(1-\delta) \frac{\rho-(1-\varphi) r}{\rho+\delta}
$$

The right-hand side is referred to as the user cost of owning, and is determined by the following parameters:

$$
\begin{array}{ll}
\theta: & \text { down payment fraction } \\
\rho: & \text { discount rate } \\
(1-\varphi) r: & \text { mortgage rate (assumed constant) after tax deduction } \\
\tau: & \text { property taxes, maintenance, insurance (as fraction of } P \text { ) } \\
g: & \text { growth rate of } R \text { and } \tau \\
\delta: & \text { mobility rate }
\end{array}
$$

\footnotetext{
${ }^{3}$ As discussed in the next section, this is for example the case for the simple user cost model in which we evaluate the effect of a change in the mortgage rate while holding the discount rate fixed. Glaeser et al. (2013) extend that model to allow for endogenous housing supply.
} 
The commonly used "asset market approach" (Poterba, 1984; Himmelberg et al., 2005) assumes $\rho=(1-\varphi) r$, which simplifies the equilibrium rent-to-price ratio to:

$$
\frac{R}{P}=(1-\varphi) r+\tau-g
$$

Thus, when the discount rate equals the (after-tax) mortgage rate, the model predicts that the down payment fraction does not matter for house prices-the rent-to-price ratio is determined only by after-tax mortgage rates, the non-interest cost of homeownership, and the growth rate of rents. However, in the more general version (2.1), house prices will decrease in $\theta$ whenever the discount rate exceeds the interest rate. As usual in asset pricing, the discount rate here should be thought of as the "effective" discount rate with which a household values current and future marginal consumption, or their shadow cost of funds. ${ }^{4}$

We can use expression (2.1) along with parameter values to calculate the predicted semi-elasticity of house prices to changes in the mortgage rate or the down payment fraction: $\frac{\partial \log (P)}{\partial x}$ where $x=r, \theta$. Note that if we take housing supply and rents as exogenous and fixed, as in the basic user cost model, then prices are directly determined by demand. In this case, the elasticity of the equilibrium price thus corresponds to the elasticity of demand, which is what we will measure in our survey.

In line with the parameters used in our survey (discussed in the next section) we assume $\varphi=$ 0.34 and $\tau=0.0335$; we furthermore set $\delta=0.06$ (following Glaeser et al., 2013) and $g=0.02$. We evaluate the semi-elasticities at $r=0.055$ (the average mortgage rate in our survey) and $\theta=0.2$ (the baseline down payment fraction), for different values of the discount rate $\rho$ :

\begin{tabular}{c|c|c|c} 
& $\rho=0.0363$ & $\rho=0.1$ & $\rho=0.2$ \\
\hline$-\frac{\partial \log (P)}{\partial r}$ & 8.53 & 6.80 & 5.32 \\
$-\frac{\partial \log (P)}{\partial \theta}$ & 0 & 0.82 & 1.65
\end{tabular}

In the first column, we set $\rho=(1-\varphi) r$. At that value, the semi-elasticity with respect to interest rates is predicted to equal 8.5, meaning a two percentage point change in the mortgage rate (as implemented in our survey) is predicted to change $P$ by about $17 \%$. On the other hand, as discussed above, a change in the down payment requirement $\theta$ would not affect $P$. Moving to the right, we

\footnotetext{
${ }^{4}$ Formally, if $\tilde{\rho}$ reflects a households' intrinsic preference for the present, and $u(\cdot)$ is its time-separable utility function over consumption, then (abstracting from uncertainty) $1+\rho=(1+\tilde{\rho}) \frac{u^{\prime}\left(c_{t}\right)}{u^{\prime}\left(c_{t+1}\right)}$, meaning that if consumption today is relatively low, the effective discount rate is high.
} 
see that as the effective discount rate increases, the predicted sensitivity to interest rates decreases somewhat (this occurs because $P$ in (2.1) is convex in the user cost). ${ }^{5}$ Furthermore, $P$ now decreases in the down payment fraction $\theta$, and the quantitative effect can be large: a semi-elasticity of 1.6 implies that a decrease in $\theta$ from $20 \%$ to $5 \%$ (as in our survey) would increase $P$ by about $24 \%$.

The predictions from the user cost model are quite sensitive to the chosen parameter values. For instance, setting $\delta=0$ would lower the semi-elasticity with respect to $r$ to between 4.7 and 5.8 (while the sensitivity with respect to $\theta$ changes little). On the other hand, as $\theta$ decreases, both semi-elasticities increase. Glaeser et al. (2013) discuss several extensions of the model that may substantially affect the sensitivity of $P$ to $r$ and $\theta$. In particular, allowing for stochastic interest rates and refinancing (when it is in the borrower's interest to do so) can substantially lower the semi-elasticity with respect to rates. ${ }^{6}$

It is furthermore important to note that these calculations treat $\rho$ as fixed. If we allowed $\rho$ to move one-for-one with $(1-\varphi) r$, as in the asset market approach, the predicted impact of a rate change on $P$ would increase by about half using the parameters above, and may increase substantially more using different parameter combinations. For instance, the calibrations in Himmelberg et al. (2005) imply a semi-elasticity of prices with respect to $r$ of about 20.

Outside the basic user cost model, which is most often used to gauge the sensitivity of house prices to interest rates, a number of papers have studied the theoretical effects of down payment restrictions. For instance, Stein (1995) emphasizes their importance for house prices and transaction volumes, while Ortalo-Magne and Rady (2006) discuss the interaction of income shocks and credit constraints in determining housing market dynamics in a model with heterogeneous households. ${ }^{7}$ Favilukis et al. (2013) study a rich general equilibrium model with heterogeneous households and incomplete markets, and find that a decrease in housing transactions costs along with a lowering of down payment requirements (from $25 \%$ to $1 \%$ in their computational experiment) can generate a house price boom close to that experienced in the US over 2000-2006. This happens in their model primarily because the improved risk-sharing opportunities from financial liberalization lower equilibrium risk premia. On the other hand, Justiniano et al. (2013) study the effects of an exogenous increase in mortgage LTV ratios in a standard DSGE model with two types of agents (borrowers

\footnotetext{
${ }^{5}$ Similarly, the semi-elasticity of prices to rates increases when rates are already low, a prediction emphasized by Himmelberg et al. (2005).

${ }^{6}$ The basic user cost model also ignores transaction costs; see Diaz and Luengo-Prado (2008) for a version of the model that incorporates such costs and also an explicit life-cycle structure.

${ }^{7}$ Davis and Van Nieuwerburgh (2014) provide a thorough overview of the literature studying housing choices over the life cycle, as well as other work at the intersection of macroeconomics, finance, and housing.
} 
and lenders), and find that such credit liberalization does not increase house prices by much within that model and also fails to match the debt-to-real-estate ratio observed empirically during and after the boom.

\subsection{Review of related empirical literature}

A substantial empirical literature studies the effects of interest rates on the housing market. The most common approach is to use either a single (national) house price series and model its evolution using vector autoregressions (VARs), or panel data on different countries or states. Two recent papers that contribute to and survey this literature are Dokko et al. (2011) and Kuttner (2014). Both papers emphasize that the effects of interest rates on house prices empirically appear to be quite modest, and too small to explain the run-up in house prices (in the US and other countries) in the early 2000s. In particular, Kuttner (2014) reviews a number of recent time-series studies that estimate the effects of 25 basis point monetary policy shocks (corresponding approximately to a 10 basis point decrease in long-term rates) on house prices to be between 0.3 and $0.9 \%$. These effects would correspond approximately to a semi-elasticity of between 3 and 9 .

Only a few papers have tried to identify the effects of interest rates using cross-sectional data, since there is typically little plausibly exogenous variation in the rates available to different borrowers. An exception to this is provided by the "conforming loan limit" (CLL) in the US, which limits the size of mortgages that Fannie Mae and Freddie Mac are allowed to purchase. A substantial literature has estimated that mortgage rates are about 10-25 basis points higher above the CLL than below, and some recent work has used this local discontinuity to estimate the effect of rates on home prices or mortgage demand. Adelino et al. (2012) exploit annual increases in the CLL over 1998-2006, and find that homes more likely to be financed with a conforming loan sell at significantly higher prices; their estimates imply a local semi-elasticity of house prices to mortgage rates of between 1 and 9. ${ }^{8}$ DeFusco and Paciorek (2014) study the effect of the spread around the CLL on mortgage demand, and estimate that a one percentage point increase in the mortgage rate reduces mortgage debt by between 1.5 and $2 \%$. As we will discuss below, our quantitative estimates of average effects are roughly in line with Adelino et al. and DeFusco and Paciorek; one advantage of our setting is that we can study heterogeneity of effects in the cross-section as well as potential asymmetries between rate increases and decreases.

\footnotetext{
${ }^{8}$ Kung (2014) uses a similar strategy to study the effects of the local CLL increases implemented as part of the Economic Stimulus Act in 2008. He finds substantial positive effects on the prices of homes in Los Angeles and San Francisco that were most likely to be financed through a mortgage affected by this policy change.
} 
There has been comparatively less empirical study of the effects of down payment requirements (or equivalently, limits on LTV ratios). Duca et al. (2011) find that including the rising LTV of first-time homebuyers substantially improves the ability of an econometric time-series model to fit aggregate US house price dynamics, especially during the boom of the early- to mid-2000s. Their estimates imply that a one percentage point higher average LTV of first-time homebuyers is associated with a one percentage point increase in house price growth. On the other hand, Glaeser et al. (2013) use micro data from 89 metropolitan areas and find that the distribution of combined LTVs (using up to three liens per property) on newly purchased homes did not change substantially over 1998-2008. Consequently, these authors argue it is unlikely that increased leverage of homebuyers per se can explain much of the house price boom over this period, though they caution that they cannot control for the interaction with changing borrower characteristics. ${ }^{9}$

A recent literature has studied the effects of mortgage LTV caps, a macroprudential policy tool, on house price dynamics. ${ }^{10}$ The International Monetary Fund (2013) notes that such caps are used in (at least) 24 countries, and a variety of studies (e.g., Crowe et al., 2013) have used panel data or single-country time-series models to investigate their effects. Most studies surveyed by the IMF find that LTV caps reduce mortgage credit and house price growth. ${ }^{11}$ However, the exact magnitudes of the effects are difficult to assess and compare across countries. Furthermore, there has been relatively little discussion of how LTV caps affect different types of borrowers and segments of the housing market. One exception is Igan and Kang (2011), who use household survey data from Korea to study the effects of different changes in macroprudential measures such as LTV caps on different household types (young vs. old, first-time buyers vs. current owners).

Finally, our work adds to an emerging literature that uses strategic surveys with different hypothetical scenarios to study questions for which it is difficult to estimate effects of interest directly from naturally-occurring data. For example, Barsky et al. (1997) use surveys to elicit preference parameters, Kimball and Shapiro (2010) study the effects of wealth on labor supply, while Ameriks et al. (2011), Beshears et al. (2014) and Ameriks et al. (2015a,b) investigate the demand for annuitization and long-term care insurance, and the strength of bequest motives. Related to our focus on

\footnotetext{
${ }^{9}$ Favara and Imbs (2015) study expansions in mortgage credit (measured by loan volume and loan-to-income ratios) due to banking deregulation, and establish a causal link to local house prices that is able to explain up to one half of the increase in house prices over 1994-2005. Another strand of the literature studies the determinants of changes in the homeownership rate and tends to find larger effects of changes in down payment restrictions than of changes in mortgage rates; see Olsen and Zabel (2014) for a review.

${ }^{10}$ Other macroprudential tools applied to the real estate sector include debt-to-income restrictions or mortgage-specific bank capital buffers.

${ }^{11}$ Additionally, lower LTVs should increase bank resilience to house price decreases, since they reduce the probability of default (e.g., Foote et al. 2008, Corbae and Quintin 2015) as well as loss-given-default.
} 
the housing market, Guiso et al. (2013) ask mortgage borrowers whether they would walk away from their home at different levels of negative equity. Sharpe and Suarez (2014) look at the interest rate sensitivity of firms' investment plans based on CFOs' responses to a survey, and (similar in spirit to our results) document surprisingly small effects of rate changes (especially decreases).

\section{Survey setup and descriptive statistics}

The survey responses we analyze in this paper are from a special online survey module on housing and mortgages that is part of the Federal Reserve Bank of New York's Survey of Consumer Expectations (SCE). ${ }^{12}$ The SCE is an internet-based survey of a rotating panel of approximately 1,200 household heads, with the primary goal of eliciting expectations about a variety of economic variables, such as inflation or labor market conditions. Respondents participate in the panel for up to twelve months, with a roughly equal number rotating in and out of the panel each month. In February 2014, repeat panelists (that is, those who had participated in the survey in the prior eleven months) were invited to participate in the special module. Out of a total sample of 1,420 household heads invited to participate in the survey, 1,211 did so, implying a response rate of $85.3 \%$. The survey was fielded during February 1-28, 2014. Respondents received \$15 for completing the survey.

The housing and mortgage module contains multiple blocks of questions, some differing between owners and renters. The respondents are asked, among other things, about their expectations for home prices, their probability of moving over the next years, and the probability of buying a home. Respondents also provide information about their debt (mortgage and non-housing), their liquid savings, and their credit score range; furthermore, we have information on their zip code location, their household income, and many demographic variables from the monthly surveys. Screenshots of the survey questions analyzed in this paper are shown in Appendix A. We now provide a detailed description of the questions and underlying assumptions.

After a screen that introduces the respondents to this block of questions ${ }^{13}$, they are confronted with the baseline scenario, in which they are asked to assume that they are to move today to a town/ city similar to their current one, and that they want to buy a home, as they intend to stay for the indefinite future. Current owners are furthermore asked to assume that they are to sell their current primary residence and pay off their mortgage. We tell them that they have found a home

\footnotetext{
${ }^{12}$ See www.newyorkfed.org/microeconomics/sce.html for additional information.

${ }^{13}$ The introduction was: "In the next set of questions, we are interested in how much you would be willing and able to pay to purchase a home similar to your current primary residence. We are also interested in how you would choose to finance the purchase. We will go through 4 scenarios. As before, there are no right or wrong answers."
} 
they like and are planning on making an offer. We also provide them with an "anchor" (which we will refer to as the "appraisal"): "Homes similar to the one that you are interested in have been selling for $\$ X, "$ where for $X$ we use their assessment of the market price of their current primary residence, coming from an earlier part of the survey, rounded to the nearest $\$ 10,000 .{ }^{14}$ Respondents are then asked to think about the maximum amount they would be willing to pay for the home, taking into account how much of a down payment they would be able to make.

Q1. In the first scenario we do not let the respondents choose the relative size of their down payment; instead, we fix it to be $20 \%$. The rest of the purchase is financed with a 30 -year fixedrate mortgage with an interest rate of $r \%$, where $r$ for a given respondent is randomly chosen to be either $4.5 \%$ or $6.5 \%$ (with equal probability). We then provide respondents with two examples of what different purchase prices would imply for (i) their required down payment, and (ii) their effective total monthly payment, including maintenance costs, property taxes and insurance, and taking into account the tax deductibility of interest payments. ${ }^{15}$ To calculate the payment, we assume that maintenance costs, property taxes and insurance add up to an annual $\tau=3.35 \%$ of the appraised home value, and that the relevant marginal tax rate is $\varphi=34 \% .{ }^{16}$ Respondents are also provided with a "calculator" where they can experiment with different purchase prices and are shown corresponding down payments and monthly payments (see Appendix A). At the bottom of the page, they are then asked to enter the maximum amount they would be willing and able to pay for this home today, reminding them that they must be able to come up with the required down payment. We will refer to their answer as their willingness to pay (WTP).

Q2. After they have entered their WTP for the first scenario, the respondents move on to the next screen, where they are asked to consider the same basic scenario (with the same home they are planning to purchase, and the same mortgage rate as in Q1), but we now give them the ability to freely choose their down payment, as long as it is at least $5 \%$ of their purchase price. Respondents are then shown six example combinations of purchase prices and corresponding down payments

\footnotetext{
${ }^{14}$ Earlier in the survey, owners are asked "What do you think your home would sell for today?" while renters are asked "If the home that you currently rent were to be sold today, approximately how much do you think it would sell for?"

${ }^{15}$ The two example prices are chosen to be $25 \%$ above and below the appraisal, rounded to the nearest $\$ 10,000$.

${ }^{16} \tau$ can be decomposed into assumed maintenance costs of $2 \%$ per year, an assumed property tax rate of $1 \%$ (close to the national average), and homeowner insurance costs of $0.35 \%$ per year (which is a commonly cited rule-of-thumb). Poterba and Sinai (2008) assume these costs to sum to 3.5\% per year. The marginal tax rate we assume is slightly higher than in the literature (e.g., Glaeser et al. (2013) set $\varphi=25 \%$ ) to account for the fact that the median income of our respondents is above the national average. We obtained $34 \%$ as the sum of the 2013 marginal tax rate for a single filer earning between $\$ 87,850$ and $\$ 183,250$, which was $28 \%$, and a $6 \%$ state tax rate. This likely overstates the value of the tax deduction for at least some of our respondents with lower income; we discuss the effects on the interpretation of our results below.
} 
of either $5 \%$ or $20 \%$, and the resulting monthly payments. ${ }^{17}$ Respondents are also again provided with a calculator, where now they can enter both purchase price and down payment (subject to the $5 \%$ minimum), and are shown corresponding monthly payments. At the bottom of the page, they are asked to enter their WTP and down payment.

Q3. In the third scenario, respondents' mortgage interest rate changes by 2 percentage points: those respondents that had a 4.5\% rate in Q1 and Q2 are now subject to a 6.5\% rate, and vice-versa. We inform them what this implies for their effective monthly payment if they leave their WTP (reported in Q2) unchanged, again provide them with six examples (determined in the same way as in Q2) and a calculator, and ask them for their WTP and down payment choice.

Q4. In the final scenario, everything is as in Q3, except that respondents are told that they just inherited $\$ 100,000$ in cash, all or part of which they could use toward the down payment if they want (but they do not have to).

Some of the considerations behind our design of these questions were the following: Q1, with randomized mortgage rates across respondents, allows us to estimate the effect of rates on WTP $(\partial \log (P) / \partial r)$ for a fixed down payment fraction. It also provides evidence on how strongly respondents' willingness and ability to pay for a home correlate with a variety of control variables. Comparing Q1 and Q2 allows us to estimate the sensitivity of WTP to the down payment requirement $(\partial \log (P) / \partial \theta)$ within respondents, while the comparison of Q2 and Q3 provides a withinrespondent estimate of $(\partial \log (P) / \partial r)$. Finally, the wealth shock in Q4 can be seen as a positive shock to non-housing fundamentals (and in particular to households' financial position).

Respondents are asked to consider the same home throughout. This has the advantage that it enables us to cleanly isolate the effect of financing conditions on WTP for that home. If instead we allowed the home to change across scenarios, it would become less clear to what extent a change in WTP was driven by a change in the flow services from the home as opposed to financing conditions. In other words, in terms of the theoretical framework from Section 2, it would no longer be clear whether a change in financing conditions affects the rent-to-price ratio, since the "rent" value of the property would change. That said, it would nevertheless be interesting to extend the survey allowing respondents to change the home they consider, though it may be difficult to elicit respondents' WTP for an "undefined" home.

\footnotetext{
${ }^{17}$ The six combinations are the WTP from the first scenario, 25\% above the WTP, and 25\% below the WTP, each with a down payment of $5 \%$ and $20 \%$.
} 


\subsection{Descriptive statistics}

For the analysis, we drop respondents who do not answer all questions in this block $(n=28)$ and those with self-appraised home values in the bottom and top 2.5\% (corresponding to $\$ 20,000$ and $\$ 900,000 ; n=51) .{ }^{18}$ We also drop respondents younger than 21 or older than $70(n=70)$, and those who in total spent less than 3 minutes or more than 30 minutes on this set of questions $(n=59)$ since these respondents may not have exerted effort on thinking through the questions or may have had comprehension problems. ${ }^{19}$ This leaves us with 962 respondents for the analysis, of which 698 are current homeowners and 264 are renters.

Descriptive statistics are provided in Table 1. Some of the variables require additional explanation. The numeracy test consists of a series of five questions, based on Lipkus et al. (2001). Our measure of risk aversion is based on the answer to the question "In financial matters, are you generally a person who is fully prepared to take risks or do you try to avoid taking risks?" on a scale from 1 (not at all willing to take risks) to 10 (very willing to take risks); for the regressions we classify respondents who answer 1-3 as "risk averse" and those who answer 7-10 as "risk loving." We measure respondents' house price growth expectations over the next year based on their perception of the price of an average home in their zip code today and the price they expect this home to have a year from today ("E(HP growth, 1yr)"). ${ }^{20}$ Finally, we elicit respondents' subjective probability (on a 0-100 scale) of moving over the next three years, and their probability of buying if they moved (for those that answer $\operatorname{Pr}($ move) $\geq 5 \%$ ). In the regressions, we add dummy variables for the cases where respondents did not answer a question, so that we do not lose observations.

The table shows that there is substantial heterogeneity in terms of financial resources (home equity, liquid savings, non-housing debt, income), and that the distributions tend to be right-skewed. Also, since this is an online survey, our respondents tend to have more education and higher income than the general US population. This may partly reflect differential internet access and computer literacy across various demographics. The sample can be made representative of US household heads, by using rim target weighting to match the targets for income, education, age, and region

\footnotetext{
${ }^{18}$ There are also 44 respondents that quit the survey before reaching this block of questions.

${ }^{19}$ We demonstrate in Appendix Table A-2 that not dropping respondents based on home value, age or response time has little effect on our main results.

${ }^{20}$ We drop values in the top/bottom 2.5th percentile. Expected growth is backed out from the following two questions that are asked in an earlier part of the survey: "Consider a typical home (house/apartment) in your zip code. What is your best guess of the value of such a home as of today?" and "You estimated the current value of a typical home in your zip code to be [previous answer] dollars. Now, we would like you to think about the future value of such a home. What do you think the value of such a home will be one year from today (in February 2015)?"
} 
in the US population. ${ }^{21}$ While we report unweighted statistics in the paper, our main results are qualitatively unchanged when using sample weights (see Appendix Table A-2). The bottom part of the table shows that the average time spent on these questions was about 8 minutes; also, almost all respondents used the provided calculators at least once, and more than three-quarters used it in all four questions.

In presenting the results, we will rely on two strategies to reduce the importance of outliers, which are present in our data as one would expect with any survey-based study. When studying summary statistics (e.g., the average effects of changes in $r$ and $\theta$ ), we will present trimmed means that eliminate the most extreme $x \%$ of observations, for $x$ varying between 0 and 10 . For our regressions, we will focus on a particular subsample of 790 respondents whose responses lie within the 2.5th and 97.5th percentile for all dependent variables of interest that represent changes between two questions (since these are most severely affected by outliers). Furthermore, when studying $\log (\mathrm{WTP})$, we set WTP values below $\$ 500$ to $\$ 500$ (using higher floors does not affect results, but using lower values leads to large outliers in the distribution of $\log (\mathrm{WTP})$ ).

\section{Results}

We begin our analysis by comparing the WTP in Q1 to the self-appraised value of the respondents' home. We then discuss the effects of down payment requirements, interest rates, and a positive nonhousing wealth shock on WTP and leverage. In this section, we will primarily focus on average effects, though we will highlight how the effects differ between owners and renters. In the next section, we will further investigate the heterogeneity of the effects.

\subsection{WTP with $20 \%$ down payment requirement}

Figure 1 shows how respondents' WTP in Q1 compares to the appraisal value of the home. The first panel shows that there is a strong positive correlation, more so for owners (correlation(WTP, appraisal $)=0.84)$ than for renters (corr. $=0.56)$. Only $11 \%$ of respondents name a WTP that corresponds exactly to the appraisal amount provided to them in the question. The second and third panels show that current owners tend to be in higher-appraised homes, and that their WTP distribution is much closer to the appraisal distribution than for renters. Both the appraisal and WTP

\footnotetext{
${ }^{21}$ The sources of the targets are as follows: for income, we use the Annual Social and Economic Supplement (ASEC) of the 2010 Current Population Survey. For education, we use the 2010 American Community Survey. For age, we use the 2010 Census data for household heads, combined with estimates of total population by age. For region, we use the 2011 Census Bureau state-level population estimates.
} 
distributions are significantly different between owners and renters according to the nonparametric Mann-Whitney-Wilcoxon (henceforth MWW) test $(p<0.001)$.

In Table 2 we study the effect of being offered the low (4.5\%) mortgage rate on $\log (\mathrm{WTP})$; since the mortgage rate was randomly assigned, this can be interpreted as a causal effect. In column (1), we simply regress $\log (\mathrm{WTP})$ on a low-rate dummy, which corresponds to a comparison of means between the low- and high-rate scenarios. We see that average WTP is about $11 \%$ higher in the lowrate scenario, but the difference is not statistically significant. Furthermore, part of the difference is accounted for by differences in the appraisal value, which on average are somewhat higher for respondents in the low-rate scenario, though not in a statistically significant manner $(p=0.27)$. In the next two columns, we control for the appraisal amount: column (2) adds log(appraisal) as an explanatory variable, while column (3) directly uses the difference between $\log (\mathrm{WTP})$ and $\log$ (appraisal) as the dependent variable. In both cases, the resulting coefficient on the low-rate dummy indicates that being offered the low rate led to an increase in WTP of about 5\%, but again the effect is not statistically significant.

In the remaining columns of the table, we add additional explanatory variables, both to reduce noise (in order to potentially increase the precision of the estimated effect of the mortgage rate) and to see how much explanatory power these variables have. Across columns (4) to (6), the estimated causal effect of the low rate remains close to the estimates in columns (2) and (3) - the point estimate indicates that WTP increases by about $6 \%$-but is statistically insignificant. Column (4) shows that when not controlling for the appraisal amount, almost all variables that we would expect to correlate with living in a more or less expensive home come in significant, often with quantitatively large coefficients. The adjusted $R^{2}$ is very high for a cross-sectional regression, meaning that our control variables seem to capture much of the relevant variation across respondents.

Many of the explanatory variables lose individual statistical significance in the fifth and sixth columns, when we control for appraisal value; however, respondent wealth (especially liquid savings) remains a strong positive predictor of WTP. We also note that except for non-housing debt, all financial variables we use as controls remain statistically significant if we put them in the regressions one-by-one (see Table A-1 in the Appendix).

Finally, the expected growth in local home prices, elicited in an earlier part of the survey, enters positively but not significantly ( $p=0.16$ ) in the fourth column (where the coefficient would imply that a five percentage point higher expected house price growth rate over the next year is associated with approximately $4.5 \%$ higher WTP), but negatively in the other columns where we control for 
the appraised amount. The question of whether house price expectations affect WTP in our survey will be analyzed in more detail in Section 5.3.

\subsection{Lowering the down payment requirement to $5 \%$}

We next study the chosen down payment fractions in Q2, as well as the effect of the lower down payment requirement on WTP. Panel (a) of Figure 2 shows the cumulative distribution of down payment fractions chosen in Q2. It illustrates that a majority of our respondents, 59\% overall, prefer to make down payments lower than the initially imposed $20 \%$. However, we also note that a substantial fraction of respondents prefer to make larger down payments-this is the case for about $28 \%$ of respondents. The two separate lines for owners and renters show that the latter group tends to choose substantially lower down payments-the median down payment fractions are $9.1 \%$ for renters and $18.4 \%$ for owners, and $78 \%$ of renters would put down less than $20 \%$, compared to only $52 \%$ of owners. The distributions of down payment fractions are strongly statistically different between the two groups ( $p<0.001$, MWW test).

Panel (b) shows the cumulative distribution of changes in $\log ($ WTP) between Q2 and Q1. Overall, about $11 \%$ of respondents lower their WTP, while $46 \%$ leave their WTP unchanged. The remaining $43 \%$ increase it, often dramatically. ${ }^{22}$ This is particularly true for renters; $58 \%$ of them increase their WTP compared to Q1.

Panel (c) displays trimmed means of the difference in $\log (\mathrm{WTP})$ between Q2 and Q1. Moving from left to right in the table, a larger fraction of extreme observations are dropped. We see that after dropping outliers, the average increase in WTP is around 10-15\%. However, the table also shows that the effect is much larger for renters (who on average increase their WTP by around 40\%) than owners (who on average increase their WTP by around 6\%). This is consistent with renters having substantially higher effective discount rates, likely because they are more financially constrained. The bottom three rows show the change in average WTP as a function of the chosen down payment in Q2. We see that the respondents that choose down payment fractions of less than $10 \%$ increase their WTP very substantially relative to Q1. For those respondents who choose a down payment fraction of $20 \%$ or higher, the average WTP change is close to zero. ${ }^{23}$

\footnotetext{
${ }^{22}$ The "step" at 1.38 corresponds to 21 respondents who increase their WTP fourfold, in all but two cases making the same down payment as in Q1 (i.e., they are in both questions choosing the highest possible WTP for a fixed down payment). The change in WTP distributions from Q1 to Q2 is highly statistically significant for both owners and renters $(p<0.001$, Wilcoxon signed-rank test).

${ }^{23}$ While it may at first glance be surprising that some respondents increase their WTP even though they are not making a lower down payment than in Q1 (meaning that they were not constrained by not being able to borrow more than $80 \%$ of the purchase price), an increase in their WTP can be due to their effective discount rate being lower than the mortgage
} 


\subsection{Effects of changing the mortgage rate}

4.3.1 Effect on WTP. Panel (a) of Figure 3 shows the distribution of the within-respondent difference in $\log (\mathrm{WTP})$ between the $6.5 \%$ mortgage rate scenario and the $4.5 \%$ scenario, separately for those respondents who started with the 4.5\% rate (in Q1 and Q2) and those who started with the $6.5 \%$ rate. We see that about $40 \%$ of respondents have a lower WTP when the mortgage rate is higher, as theory would predict. However, almost half of all respondents leave their WTP unchanged between Q2 and Q3; about 10\% change their WTP in the "wrong" direction. The fraction of respondents that display a lower WTP with the $6.5 \%$ rate is somewhat higher for those who started with the low rate, pointing toward a potentially asymmetric effect of rate changes on WTP: increasing rates lowers WTPs more than lowering rates increases WTPs. The difference in distributions depending on the initial rate is statistically significant ( $p=0.03$, MWW test).

Panel (b) of the figure displays trimmed means of the difference in $\log (\mathrm{WTP})$. We see that after dropping the most extreme outliers (from $X=2.5$ onwards), the average difference in WTPs is between 4 and $5 \%$ for the full sample, as well as for the two subsamples of owners and renters. ${ }^{24}$ The fourth and fifth lines provide an estimated magnitude of the asymmetry discussed in the previous paragraph: while a $2 \%$ increase in rates lowers average WTPs by between 5 and $7 \%$, a $2 \%$ decrease in rates only increases WTPs by between 3 and $4 \%$.

The estimated average within-respondent effect of the rate change aligns well with the betweenrespondent effect estimated in Table 2 - in both cases, having access to a mortgage rate that is 2 percentage points lower on average increases WTP by around 4 to $6 \%$. Nevertheless, one may worry that the within-respondent estimate could be attenuated by respondent inertia or laziness; this is investigated in Section 5.2.

4.3.2 Effect on down payment fraction. We next turn to the effect of the rate change on the chosen down payment fraction. Panel (a) of Figure 4 shows the distribution of the within-respondent change in down payment (as a fraction of WTP) between the $6.5 \%$ scenario and the $4.5 \%$ scenario, again distinguishing between respondents depending on starting rate. Intuitively, down payments should be relatively higher when financing is more expensive, and that is indeed the case for slightly above $40 \%$ of respondents, while an equally large number leave their down payment fraction unchanged. We again note an asymmetry: down payment fractions are more likely to increase when rates go up than they are to decrease when rates drop (the distributions are strongly

rate, such that allowing them to make a down payment of more than $20 \%$ increases their WTP for the home.

${ }^{24}$ The distributions of changes are not significantly different between owners and renters ( $p=0.39$, MWW test). 
statistically different; $p<0.001$, MWW test). This is largely explained by the fact that a substantial fraction of our respondents was already making the lowest possible down payment in Q2, so that they cannot decrease their down payment fraction further after the rate decreases. Panel (b) shows that on average, the chosen down payment fraction is about 1.5 percentage points lower when the mortgage rate is $4.5 \%$ rather than $6.5 \%$, and that the size of the effect does not differ between owners and renters.

\subsection{Effect of a non-housing wealth shock}

Panel (a) of Figure 5 shows the distributions of changes in WTP and down payments after the hypothetical $\$ 100,000$ cash windfall in Q4. Roughly 45\% of respondents increase their WTP, and $76 \%$ increase their down payment; $79 \%$ increase at least one of the two. For the vast majority of respondents, these increases are less than $\$ 100,000$, meaning that they would spend some but not all of their inheritance on their house purchase.

Panel (b) displays trimmed means of the effects of the windfall, both in dollar terms and relative to Q3. On average, the cash windfall raises WTP by about $\$ 15,000$ relative to Q3, which corresponds to a relative increase of about $10 \%$. Down payments on average increase by about $\$ 35,000$ and therefore by more than WTP; the increase in the down payment fraction (that is, $\Delta$ (Down Payment/WTP)) averages about 20 percentage points. Thus, our respondents would on average spend about one-third of the cash windfall on the down payment, and their leverage would be substantially smaller in that scenario.

The table shows that the average increase in WTP, both in dollar terms and relative to the WTP in Q3, is larger for renters than for owners. Both groups increase their down payments by roughly the same amount in dollar terms, but since renters have lower WTPs and previously chose lower down payments on average, their leverage decreases by more than for owners. ${ }^{25}$

\subsection{Summary of average effects}

The table below summarizes the average effects discussed in this section, in a way (roughly) corresponding to the semi-elasticities discussed in Section 2. For the first line, we use the average within-respondent estimates of the effect of interest rates based on Q2 and Q3, while for the second line we use the average changes in WTP from Q1 to Q2. The third line adds the effect of the $\$ 100,000$

\footnotetext{
${ }^{25} \mathrm{MWW}$ tests indicate that the distributions of the variables shown in panel (b) of Figure 5 differ significantly (at $p<0.01$ ) between owners and renters, except for the down payment change in dollars.
} 
shock to wealth $(w)$ for which there is no direct model equivalent. In all cases the range we report is the range of semi-elasticities we get by trimming $2.5,5$, and $10 \%$ of outliers on each side.

\begin{tabular}{c|c|c|c|c} 
Model measure & Empirical measure & Full sample & Owners & Renters \\
\hline$-\frac{\partial \log (P)}{\partial r}$ & $-\frac{\log (P \mid r=6.5 \%)-\log (P \mid r=4.5 \%)}{0.02}$ & $1.9-2.5$ & $1.8-2.3$ & $2.1-2.4$ \\
$-\frac{\partial \log (P)}{\partial \theta}$ & $-\frac{\log (P \mid D P=20 \%)-\log (P \mid D P \geq 5 \%)}{0.15}$ & $0.6-1.2$ & $0.3-0.6$ & $2.3-3.1$ \\
N/A & $100(\log (P \mid w+100 \mathrm{k})-\log (P \mid w))$ & $7.4-13.5$ & $5.0-8.5$ & $20.4-26.7$
\end{tabular}

In Table A-2 in the Appendix, we show that these average effects are essentially unchanged if we (i) use sample weights; (ii) do not drop observations based on self-appraised home value, respondent age, or response time; or (iii) restrict the sample to respondents who state a probability of moving over the next three years of at least $20 \%$ and a probability of buying conditional on moving of at least $50 \%$ (with the idea being that this task may be more salient for them than for other respondents, and that these respondents are more likely to be marginal buyers in the market).

\section{Additional analyses}

The previous section has already shown that the effects of changes in down payment requirements and shocks to non-housing wealth differ between current owners and renters. In this section, we investigate the role of various additional characteristics in explaining heterogeneity of effects across respondents. We also conduct robustness checks on the within-respondent effect of the mortgage rate on WTP, and study whether different measures of respondents' home price growth expectations explain variation in WTP.

\subsection{Heterogeneity of effects}

5.1.1 Down payment requirements. Table 3 studies the heterogeneity in chosen down payment fractions in Q2. The first line shows that respondents facing the low interest rate choose lower down payment fractions. The magnitude of the effect is somewhat larger than the within-respondent finding from Section 4.3.2 (based on differences between Q2 and Q3, shown in Figure 4), but is quite close to DeFusco and Paciorek (2014)'s estimate that mortgage debt decreases by 1.5-2\% for a one percentage point increase in the mortgage rate. ${ }^{26}$ The rest of the table shows that respondents

\footnotetext{
${ }^{26}$ This interpretation of their findings takes house prices as fixed around the conforming loan limit. If in our data we instead looked at the effect on respondents' total amount of debt, we would get a larger sensitivity, since we find that higher rates lead to higher down payment fractions and lower WTP.
} 
with more home equity and liquid savings, higher credit scores, and less non-housing debt choose to make larger down payments. Perhaps surprisingly, relatively higher income respondents choose lower down payments (once we control for wealth); this may be due to higher income being associated with more capacity to make monthly payments, or with these respondents having access to better outside investment options. The owner dummy switches sign depending on whether or not equity is included as an explanatory variable; this is because when we do include it, renters (who have zero equity) and owners with zero or negative equity are both in the omitted category of the equity variable, and thus the owner dummy should be interpreted as the difference between renters and negative equity owners (with the latter choosing lower down payments on average). It is interesting to note that respondent age and numeracy have statistically and economically significant effects on chosen down payment fractions: the regression implies that a 50-year old respondent on average makes a 5 percentage points larger down payment than a 30-year old, holding other observables constant (based on the last column). The numeracy test results in a score of 0 to 5 , meaning that the highest scorers are predicted to make about a 12 percentage point larger down payment than those in the lowest category.

Table 4 instead studies heterogeneity in the effect that the loosening of the down payment requirement has on WTP (based on comparing Q2 and Q1). It shows that the increase in WTP is particularly large for respondents with negative or zero equity (which includes renters), low liquid savings, and low credit scores. The low-rate scenario is similarly associated with less of a response of WTP. This is potentially due to WTP already being slightly higher for the low-rate respondents in Q1.

5.1.2 Within-respondent interest rate change. A regression analysis of the change in $\log (\mathrm{WTP})$ between Q2 and Q3, shown in Table 5, reveals little evidence of systematic heterogeneity in the reaction to a rate change-none of the balance sheet and income variables used in the previous regressions have significant explanatory power, although there is some evidence that owners react less to the rate change than renters. Another variable that is significant in some specifications (when not separately controlling for equity) is the down payment fraction in Q2, which reduces the reaction to the rate change. This is intuitive: the higher the down payment, the less the monthly payment is affected by a change in rates. ${ }^{27}$

\footnotetext{
${ }^{27}$ In this regression, the starting rate does not enter significantly, even though we had seen in the previous section that there appears to be a significant asymmetry, based on nonparametric analysis. The lack of significance here is driven by a small number of outliers $(<5)$; once they are removed, the coefficient doubles in size and becomes statistically significant.
} 
5.1.3 Wealth shock. Table 6 displays results from regressions similar to the previous ones, but looking at the relative change in WTP in response to the $\$ 100,000$ cash windfall in Q4. Again, respondents in a relatively worse financial position (e.g., little liquid savings, low credit scores), as well as renters, increase their WTP by more. Interestingly, married respondents (about two-thirds of our sample) increase their WTP by less in relative terms in response to the wealth shock.

5.1.4 Owners vs. renters. Much of the heterogeneity in our sample comes from differences in characteristics between owners and renters, with the former generally having higher wealth, better credit scores, and higher incomes. To ensure that the detected effects of observable characteristics discussed above are not just driven by differences between owners and renters, Tables A-3 to A5 repeat the main regressions in which we detected heterogeneity, using only the owner sample. Results are generally very similar: the WTP of owners that are in a better financial position (more equity; more liquid savings; less debt; higher credit scores; higher income) tends to react less to a relaxation in down payment requirements or a wealth shock, and (with the exception of income) these characteristics are associated with higher down payment fractions in Q2.

\subsection{Non-response to interest rate changes}

In Section 4.3 (Figure 3), we documented that almost half of our respondents did not adjust their WTP in response to a change in the mortgage rate (from $4.5 \%$ to $6.5 \%$ or vice-versa), which contributes to the overall average effect of the change in rate on WTP being rather small. A potential concern with this finding is that it may not capture how respondents would react to such a change in reality; instead it may reflect respondent inertia, laziness, or the desire to complete the survey as quickly as possible. Although it is difficult to entirely rule out that at least some responses were affected by these factors, we now present some evidence suggesting that this was not the main driver behind the muted average reaction to the rate change.

Table 7 shows trimmed means of the within-respondent difference in $\log (\mathrm{WTP})$ between the high- and low-interest scenarios, for different subsamples of respondents for which it seems less likely that they did not exert effort on the relevant questions. It also displays in each case the fraction of respondents that leave their WTP unchanged when moving from Q2 to Q3. As a benchmark, the first row shows the statistics for the full sample. Next, rows 2 and 3 focus on respondents that used the calculator provided on the screen, either just in Q3 or in all questions. As most respondents do so, the resulting averages, while slightly larger in magnitude than in the full sample (as 
predicted if this restriction weeds out some "unmotivated" respondents), are not materially different from the full sample. ${ }^{28}$ Row 4 instead looks at respondents that spent more time than the median respondent on Q3, as that might proxy for them exerting effort to think through the question. Again, this restriction has only a rather small impact on the trimmed mean change, even though the fraction of respondents that leave their WTP unchanged is six percentage points lower than in the full sample.

In the next row, we only include respondents that make a change to either WTP or down payment in the subsequent question, Q4. The idea here is that if some respondents were just trying to get through the survey as quickly as possible, and therefore do not react to the change in the interest rate and their monthly payment in Q3, we would expect them to not change their answer in Q4 either. However, as noted in Section 4.4, most respondents do react to the wealth shock, and therefore this restriction does not have a large effect on the mean either. In row 6, we exclude respondents whose WTP in Q2 is equal to their "appraisal," since these respondents might just stick to setting their WTP equal to the "fundamental" value of the home throughout, irrespective of the financing terms. The final row implements the union of all the restrictions in rows 2 to 7 , and shows that even then the resulting trimmed means are barely changed relative to the full sample.

This analysis suggests that respondent inertia or laziness had only a minor attenuating impact on the effect of the change in mortgage rate. Also, recall that the within-respondent effect is very similar in magnitude to the between-respondent effect of changes in the mortgage rate estimated from Q1.

\subsection{The role of expectations}

A number of recent contributions have explored the role of (heterogeneous) beliefs about future price growth in generating observed house price cycles (e.g., Burnside et al., 2011; Case et al., 2012; Piazzesi and Schneider, 2009). Since we have direct measures of expectations of future house price changes in our data, it is interesting to check whether differences in these expectations across respondents affect their WTP, with and without controlling for other factors.

In addition to the measure of expected house price growth in the respondent's zip code that we have included in our regressions throughout (E(HP growth, 1yr), described in Section 3.1), we also use an alternative binary measure, based on whether respondents think that buying property in

\footnotetext{
${ }^{28}$ The distributions of WTP changes are not statistically different from the full sample for any subsample in rows 2 to 7 of the table (MWW tests yield $p>0.3$ in all cases).
} 
their zip code is a good financial investment. ${ }^{29}$ We note that both of these measures were elicited for the zip code in which a respondent currently lives, not the hypothetical town/city we ask our respondents to think about, but since we specify that it is similar to their current town/city, it seems plausible that their house price expectations would be similar as well.

In Table 2, we found a positive but insignificant effect of E(HP growth, 1yr) on WTP in Q1 when not controlling for the appraisal value of the home; this effect switched signs (though remained statistically insignificant) once $\log$ (appraisal) was added to the regression. This finding is reproduced in columns (1) to (3) of panel (a) of Table 8. Columns (4) and (5) of the same table show that the binary measure of whether a respondent believes buying property is a good investment is more strongly correlated with $\log (\mathrm{WTP})$ in Q1 as long as we do not control for appraisal value of the home, suggesting that it is less noisy than the continuous measure. However, the last column shows that once we do control for appraisal, the belief variable is no longer significant.

Panel (b) of the table shows that the pattern observed in panel (a) is explained by both measures of beliefs being significantly correlated with a respondent's self-assessed home value. Thus, even after controlling for other observable (financial) characteristics of the respondents, those who are more optimistic about future house prices report living in more expensive homes. This could be due either to them being overly optimistic about the price of their current home, or to them already living in a relatively larger home (due to past optimism about house prices). Either way, this analysis suggests that heterogeneity in house price expectations may lead to differences in WTP across respondents, but that in our regressions this is mostly picked up by the appraisal measure.

\section{Discussion and conclusion}

The main findings from the previous sections can be summarized as follows: first, our survey respondents' willingness to pay for a home is not very sensitive to a relatively substantial change in the mortgage rate. Both between and within respondents, we estimate the effect of a 2 percentage point change in the mortgage rate on WTP to be around $5 \%$ on average. Second, a decrease in the required down payment fraction has much larger effects on WTP, though there is significant heterogeneity in the cross-section: for instance, the renters in our sample (who choose lower down

\footnotetext{
${ }^{29}$ The exact question from an earlier part of the survey is: "If someone had a large sum of money that they wanted to invest, would you say that relative to other possible financial investments, buying property in your zip code today is (1) A very good investment; (2) A somewhat good investment; (3) Neither good nor bad as an investment; (4) A somewhat bad investment; (5) A very bad investment." The dummy in our regression is set to 1 for the $60.2 \%$ of respondents that picked (1) or (2).
} 
payments) increase their WTP on average by more than $40 \%$, while for owners the average increase is only around $6 \%$. Third, a positive non-housing wealth shock has large effects on our respondents' WTP as well: a $\$ 100,000$ cash inheritance on average leads to a 10\% increase in WTP, with the effect being almost four times larger for renters than for owners. Interestingly, with the additional cash available, our respondents choose to make substantially larger down payments, suggesting that for many of them the earlier choice of high leverage is due to liquidity constraints rather than a desire to "lever up."

The estimated effect of the mortgage rate on WTP corresponds to a semi-elasticity of about 2.5, which is within (though toward the lower end of) the range of recent estimates in the literature. In particular, as discussed in Section 2, based on micro data Adelino et al. (2012) estimate a local semi-elasticity of house prices to rates in the range of 1 to 9 , while at the macro level, the studies reviewed in Kuttner (2014) find effects approximately corresponding to a semi-elasticity of between 3 and 9. Importantly, one might expect the macro semi-elasticities to be larger than those found in micro data or in our survey, since a decrease in the entire term structure of interest rates, not just the mortgage rate as in our case, is likely to lower effective discount rates $\rho$ and therefore have larger effects on house prices. ${ }^{30}$ Furthermore, in reality lower rates may allow some borrowers to qualify for a larger loan because they loosen payment-to-income constraints, which are absent from our setting. On the other hand, housing supply (at least in some regions) would respond to a change in demand, which in turn would dampen the effect of lower rates on house prices.

The semi-elasticity we find is well below the prediction of the calibrated user cost model in Section 2, which generated semi-elasticities between 5 and 8 . In that sense, our results can be seen as reinforcing the "puzzle [of] why house prices are less sensitive to interest rates than theory says they should be" (Kuttner, 2014). Our survey does not give strong hints as to why our respondents react little to rates. One possibility is that the change in the effective monthly payment in response to the interest rate change, although nonnegligible on its own (especially if discounted over the life of the loan), appears small relative to the required down payment, and therefore respondents do not feel compelled to adjust their WTP. ${ }^{31}$ An alternative and perhaps more sophisticated explanation might be that respondents have the intuitive theory that periods with low rates tend to coincide with higher risk premia, which in turn may prevent them from substantially increasing their WTP

\footnotetext{
${ }^{30}$ Low interest rates could also affect house prices indirectly, if they induce banks to make riskier loans (for instance, with lower down payments) in a "search for yield" (e.g., Maddaloni and Peydro, 2011).

${ }^{31}$ The average (median) change in the after-tax monthly payment when the mortgage rate changes by 2 percentage points between Q2 and Q3 (and leaving WTP and down payment unchanged) is \$104 (\$85).
} 
relative to a higher-rate scenario. ${ }^{32}$

One limitation of our setup is that we do not explicitly specify whether respondents have the ability to refinance their mortgage. While this does not affect the validity of our results, it may affect the prediction of the user cost model: as emphasized by Glaeser et al. (2013), allowing for refinancing can substantially lower the sensitivity of prices to changes in rates, and may realign the model predictions with our results. That said, it is questionable whether our respondents thought about the possibility of refinancing their hypothetical mortgage into a lower rate.

Another potential concern is that we show after-tax monthly payments, assuming a constant marginal tax rate for all respondents. However, in reality some of our respondents would face a lower marginal tax rate, or they might not deduct interest payments at all (so that effectively $\varphi=0$ ). This would imply that the (relative) change in effective monthly payments that we show to our respondents would arise from smaller changes in interest rates, and therefore we might understate the sensitivity of WTP to rate changes. To bound the possible size of this understatement, make the extreme assumption $\varphi=0$ (meaning no tax deductions of interest payments). In this case, the rate change that would produce the same relative change in effective monthly payments is about 1.35 percentage points (rather than 2 percentage points). Correspondingly, the semi-elasticity to rates implied by the survey responses would increase to almost 4 . Of course the predicted sensitivity from the user cost model would similarly increase; thus, the qualitative conclusion that WTP seems less responsive than predicted by the model remains valid.

While the sensitivity of WTP to the mortgage rate is quite small, changes in down payment requirements have large effects on WTP in our survey. This suggests that changing availability of credit, as well as macroprudential measures such as LTV caps, can have a large influence on house prices. Furthermore, we have seen that these effects are substantially stronger for relatively less wealthy respondents, meaning that the effect of credit availability varies substantially in the cross-section of households, as emphasized by Landvoigt et al. (2015). Similarly, to the extent that households overall are richer when economic conditions are good, a loosening of credit may have less of an effect on housing demand during those times than during bad times.

The importance of non-housing fundamentals for housing demand is also illustrated, though admittedly in a stylized way, by the effects of the cash windfall. Making our respondents wealthier substantially increases the amount they would spend on their home purchase, and reduces the chosen leverage. Of course, this again should be seen as a partial equilibrium effect, since appraisal

\footnotetext{
${ }^{32}$ The risk premia channel is emphasized by Favilukis et al. (2013).
} 
values would generally respond to overall economic conditions as well. It would be very interesting to see how the results found here would change with economic conditions, or if the same survey questions were fielded in another country.

The approach used in this paper of eliciting stated willingness to pay under different counterfactual scenarios illustrates the potential of using "direct" albeit stylized methods to identify important policy parameters of interest, with minimal assumptions. Furthermore, we show how this method can be a powerful tool to understand underlying heterogeneity in consumer behavior, which otherwise is very difficult to investigate with real-word observational data due to confounds and lack of exogenous variation in fundamentals. The meaningful variation that we document in the databoth across scenarios and across different groups of respondents-suggests that consumers have the ability and willingness to answer such (relatively complicated) questions. In future work, our approach could be adapted to understand the importance of other mortgage contract characteristics (such as the term of the mortgage, or whether it has a fixed or adjustable rate) for housing demand and financing choices. Furthermore, since there is little direct evidence on the role that home price expectations play in housing cycles, one could extend our current framework by exogenously manipulating individuals' home price expectations and analyzing their effect on housing demand. 


\section{References}

Adelino, M., A. SchoAr, AND F. Severino (2012): “Credit Supply and House Prices: Evidence from Mortgage Market Segmentation," Working paper, MIT Sloan.

Ameriks, J., J. S. Briggs, A. CAPlin, M. D. Shapiro, And C. Tonetti (2015a): “Long-term Care Insurance, Annuities, and the Under-Insurance Puzzle," Working paper, Vanguard Research Initiative.

— (2015b): “Long-Term Care Utility and Late in Life Saving," Working Paper 20973, NBER.

Ameriks, J., A. CAplin, S. LAufer, AND S. VAN Nieuwerburgh (2011): "The Joy of Giving or Assisted Living? Using Strategic Surveys to Separate Public Care Aversion from Bequest Motives," Journal of Finance, 66, 519-561.

BArsky, R. B., F. T. Juster, M. S. Kimball, And M. D. Shapiro (1997): "Preference Parameters and Behavioral Heterogeneity: An Experimental Approach in the Health and Retirement Study," Quarterly Journal of Economics, 112, 537-579.

BERNANKE, B. S. (2005): “The Global Saving Glut and the U.S. Current Account Deficit," Speech delivered at the Sandridge Lecture, Virginia Association of Economists, Richmond, Va., March 10 .

Beshears, J., J. J. Choi, D. Laibson, B. C. Madrian, And S. P. Zeldes (2014): “What makes annuitization more appealing?" Journal of Public Economics, 116, 2-16.

Burnside, C., M. Eichenbaum, And S. Rebelo (2011): “Understanding Booms and Busts in Housing Markets," Working Paper 16734, NBER.

Case, K. E., R. J. Shiller, And A. K. Thompson (2012): “What Have They Been Thinking? Homebuyer Behavior in Hot and Cold Markets," Brookings Papers on Economic Activity, Fall, 265298.

CORBAE, D. AND E. QUinTIN (2015): “Leverage and the Foreclosure Crisis," Journal of Political Economy, 123, 1-65.

Crowe, C., G. Dell' Ariccia, D. IgAN, And P. RABAnal (2013): “How to deal with real estate booms: Lessons from country experiences," Journal of Financial Stability, 9, 300-319.

Davis, M. A. And S. VAn Nieuwerburgh (2014): "Housing, Finance and the Macroeconomy," Working Paper 20287, NBER.

DeFusco, A. A. AND A. PACIOREK (2014): “The Interest Rate Elasticity of Mortgage Demand: Evidence From Bunching at the Conforming Loan Limit," Finance and Economics Discussion Series 2014-11, Federal Reserve Board.

Delavande, A. And C. F. MANSKI (2010): "Probabilistic Polling and Voting in the 2008 Presidential Election: Evidence from the American Life Panel," Public Opinion Quarterly, 74, 433-459.

Diaz, A. And M. J. Luengo-Prado (2008): “On the user cost and homeownership," Review of Economic Dynamics, 11, 584-613.

DokKo, J., B. M. Doyle, M. T. Kiley, J. Kim, S. Sherlund, J. Sim, And S. VAn Den Heuvel (2011): "Monetary policy and the global housing bubble," Economic Policy, 26, 237-287. 
DucA, J. V., J. Muellbauer, And A. Murphy (2011): “House Prices and Credit Constraints: Making Sense of the US Experience," Economic Journal, 121, 533-551.

FAVARA, G. AND J. ImbS (2015): "Credit Supply and the Price of Housing," American Economic Review, 105, 958-992.

FAVilukis, J., S. C. Ludvigson, AND S. VAN NieuWerburgh (2013): “The Macroeconomic Effects of Housing Wealth, Housing Finance, and Limited Risk-Sharing in General Equilibrium," Working paper, NYU.

Foote, C. L., K. GERARDi, AND P. S. Willen (2008): “Negative equity and foreclosure: Theory and evidence," Journal of Urban Economics, 64, 234-245.

Glaeser, E. L., J. D. Gottlieb, AND J. Gyourko (2013): “Can Cheap Credit Explain the Housing Boom?" in Housing and the Financial Crisis, ed. by E. L. Glaeser and T. Sinai, University of Chicago Press, 301-359.

Guiso, L., P. SAPIENZA, AND L. Zingales (2013): “The Determinants of Attitudes toward Strategic Default on Mortgages," Journal of Finance, 68, 1473-1515.

Hendershott, P. And J. Slemrod (1983): “Taxes and the User Cost of Capital for OwnerOccupied Housing," Journal of the American Real Estate and Urban Economics Association, 10, 375393.

Hensher, D. A. AND M. BRAdLey (1993): “Using stated response choice data to enrich revealed preference discrete choice models," Marketing Letters, 4, 139-151.

HimmelberG, C., C. Mayer, And T. Sinai (2005): “Assessing High House Prices: Bubbles, Fundamentals and Misperceptions," Journal of Economic Perspectives, 19, 67-92.

IGAN, D. AND H. KANG (2011): "Do Loan-to-Value and Debt-to-Income Limits Work? Evidence from Korea," Working Paper 11/297, IMF.

International Monetary Fund (2013): “Key Aspects of Macroprudential Policy - Background Paper," available at www.imf .org/external/np/pp/eng/2013/061013C . pdf.

Justiniano, A., G. E. Primiceri, And A. TAmbalotti (2013): “Household Leveraging and Deleveraging," Working Paper 18941, NBER.

Kimball, M. S. AND M. D. Shapiro (2010): “Labor Supply: Are the Income and Substitution Effects Both Large or Both Small?" Working paper, University of Michigan.

KUnG, E. (2014): “The Effect of Credit Availability on House Prices: Evidence from the Economic Stimulus Act of 2008," Working paper, UCLA.

KutTner, K. N. (2014): “Low Interest Rates and Housing Bubbles: Still No Smoking Gun," in The Role of Central Banks in Financial Stability: How Has It Changed?, World Scientific, 159-185.

Landvoigt, T., M. Piazzesi, And M. Schneider (2015): “The Housing Market(s) of San Diego,” American Economic Review, 105, 1371-1407.

LipKUS, I. M., G. SAMSA, AND B. K. Rimer (2001): "General Performance on a Numeracy Scale among Highly Educated Samples," Medical Decision Making, 21, 37-44. 
Maddaloni, A. ANd J.-L. Peydro (2011): “Bank Risk-taking, Securitization, Supervision, and Low Interest Rates: Evidence from the Euro-area and the U.S. Lending Standards," Review of Financial Studies, 24, 2121-2165.

Olsen, E. O. And J. E. ZABel (2014): "United States Housing Policy," in Handbook of Regional and Urban Economics, Volume 5, forthcoming.

Ortalo-Magne, F. AND S. Rady (2006): "Housing Market Dynamics: On the Contribution of Income Shocks and Credit Constraints," Review of Economic Studies, 73, 459-485.

PiAZZESI, M. AND M. SCHNeIdeR (2009): "Momentum Traders in the Housing Market: Survey Evidence and a Search Model," American Economic Review, 99, 406-411.

Poterba, J. AND T. SinAi (2008): “Tax Expenditures for Owner-Occupied Housing: Deductions for Property Taxes and Mortgage Interest and the Exclusion of Imputed Rental Income," American Economic Review, 98, 84-89.

PoterbA, J. M. (1984): “Tax Subsidies to Owner-Occupied Housing: An Asset-Market Approach," Quarterly Journal of Economics, 99, 729-752.

Sharpe, S. A. AND G. A. SuArez (2014): "The Insensitivity of Investment to Interest Rates: Evidence from a Survey of CFOs," Finance and Economics Discussion Series 2014-02, Federal Reserve Board.

SteIN, J. C. (1995): "Prices and Trading Volume in the Housing Market: A Model with DownPayment Effects," Quarterly Journal of Economics, 110, 379-406.

SVENSSON, L. E. (2013): "The Effect on Housing Prices of Changes in Mortgage Rates and Taxes," Working paper, larseosvensson.se.

TAYLOR, J. B. (2009): “The Financial Crisis and the Policy Responses: An Empirical Analysis of What Went Wrong," Working Paper 14631, NBER.

Yellen, J. L. (2014): “Monetary Policy and Financial Stability," Michel Camdessus Central Banking Lecture at the International Monetary Fund, July 2, 2014. 


\section{Figure 1. Willingness to pay in Q1 and appraisal amounts.}

In panel (a), WTP is winsorized at $\$ 900,000$; in panels (b) and (c), WTP and appraisal amounts are winsorized at $\$ 600,000$.

(a) WTP in Q1 vs. appraisal for all respondents

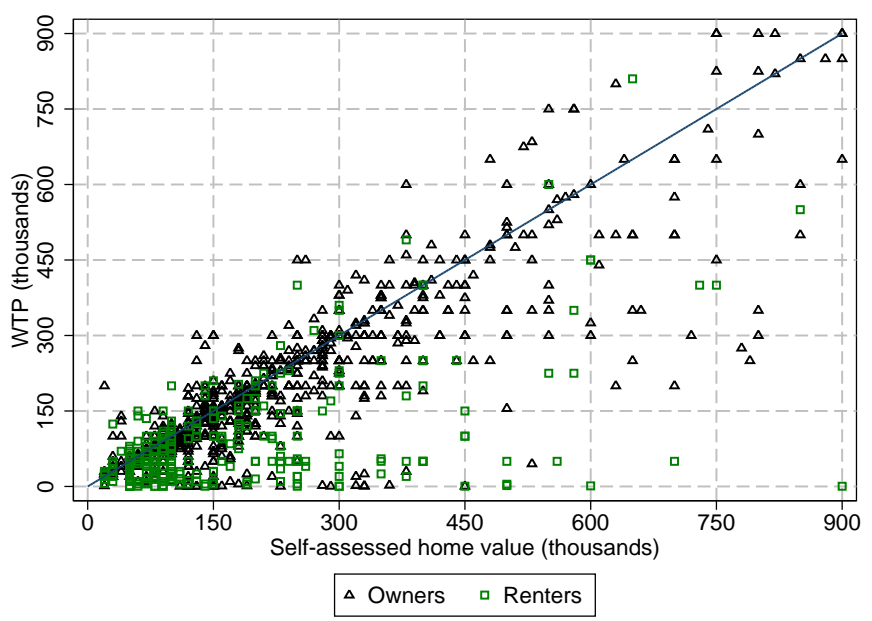

(b) Cumulative distributions for owners

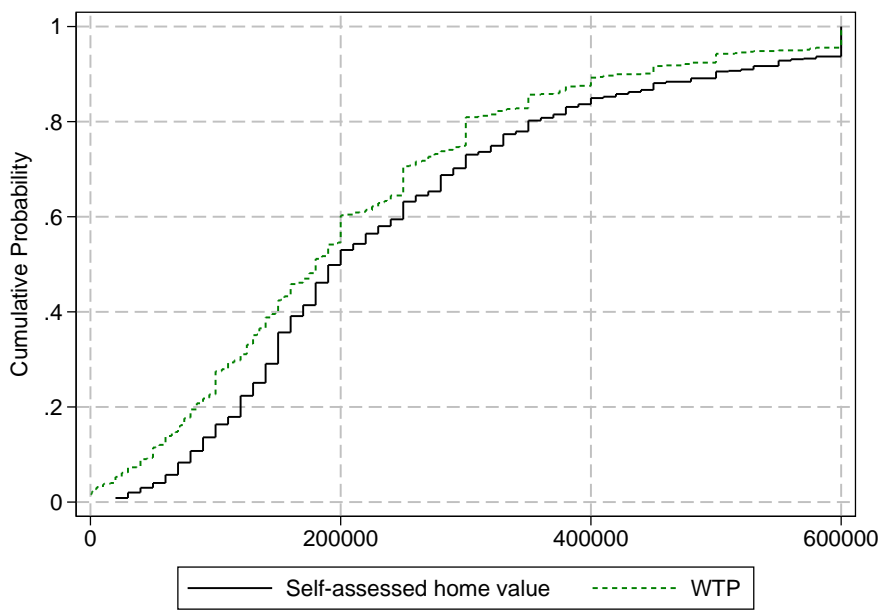

(c) Cumulative distributions for renters

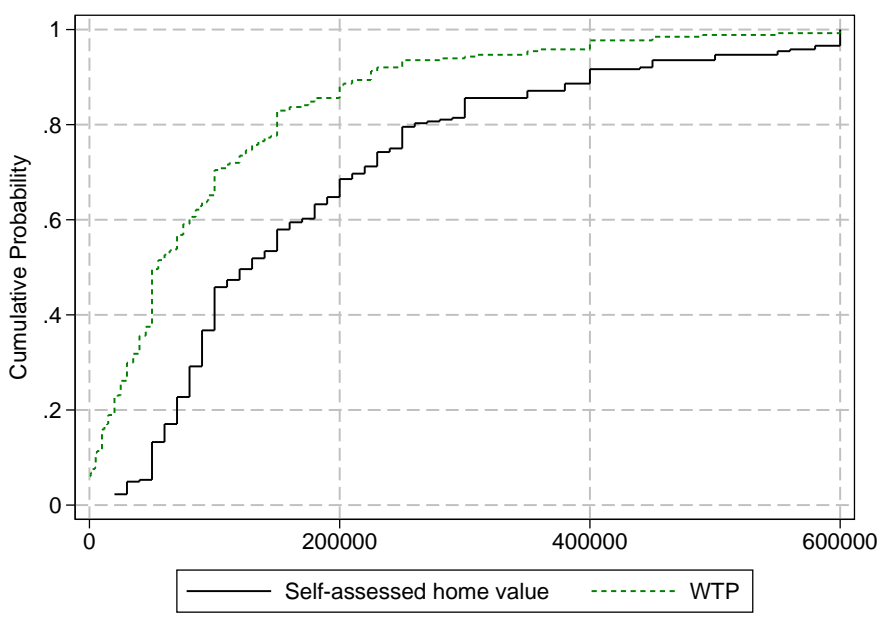




\section{Figure 2. Effects of lowering the down payment requirement.}

Panel (a) displays the distribution of down payment fractions in Q2. Panel (b) displays the distribution of within-respondent changes in $\log (\mathrm{WTP})$ between Q2 and Q1 (winsorized at -0.2 and 1.5 in chart), and panel (c) shows trimmed means of the same variable. DP stands for down payment.

(a) Distribution of down payment fraction in Q2

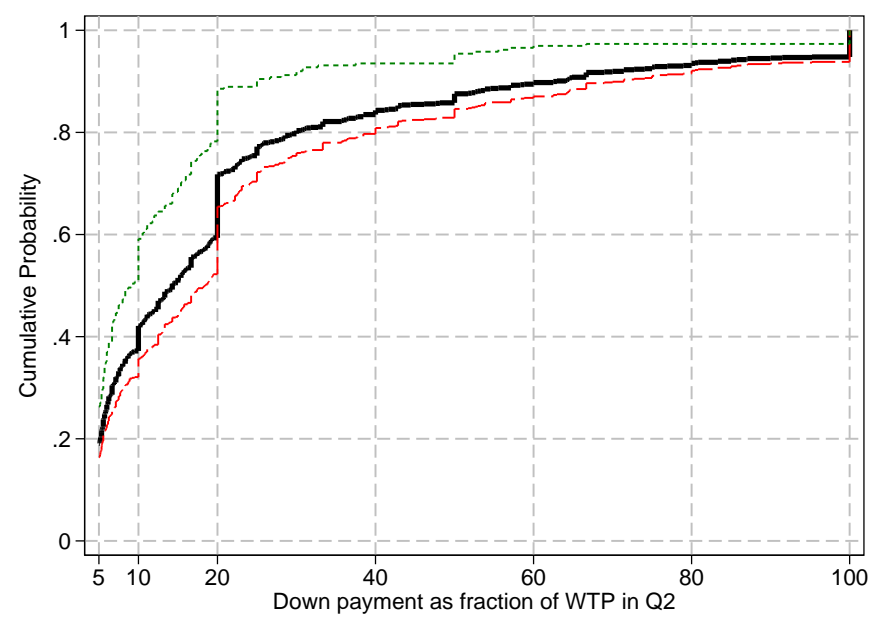

(b) Distribution of effect of lower down payment requirement on WTP

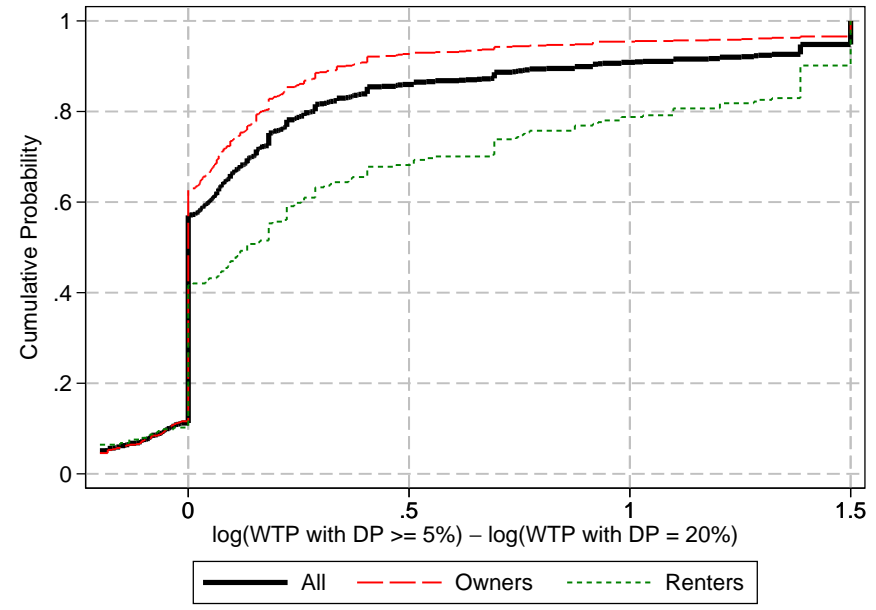

(c) Average difference between $\log ($ WTP with DP $\geq 5 \%)$ and $\log ($ WTP with DP $=20 \%)$

\begin{tabular}{llllll}
\hline Sample & N & \multicolumn{4}{l}{ Trimmed mean without top/bottom $\mathbf{X \%}$} \\
\hline & & $X=0$ & $X=2.5$ & $X=5$ & $X=10$ \\
\hline Full & 962 & $0.256^{*}$ & $0.185^{*}$ & $0.152^{*}$ & $0.097^{*}$ \\
Owners & 698 & $0.159^{*}$ & $0.093^{*}$ & $0.064^{*}$ & $0.048^{*}$ \\
Renters & 264 & $0.513^{*}$ & $0.462^{*}$ & $0.395^{*}$ & $0.351^{*}$ \\
$\mathrm{DP}_{\mathrm{Q} 2}<10 \%$ & 356 & $0.565^{*}$ & $0.462^{*}$ & $0.405^{*}$ & $0.333^{*}$ \\
$\mathrm{DP}_{\mathrm{Q} 2} \in[10 \%, 20 \%)$ & 212 & $0.134^{*}$ & $0.100^{*}$ & $0.081^{*}$ & $0.069^{*}$ \\
$\mathrm{DP}_{\mathrm{Q} 2} \geq 20 \%$ & 394 & 0.043 & $0.025^{*}$ & $0.020^{*}$ & $0.016^{*}$
\end{tabular}

${ }^{*}$ denotes statistical significance at $p<0.05$ (two-tailed $t$-test). 
Figure 3. Effect of mortgage rate changes on WTP. Panel (a) displays the within-respondent difference in $\log (\mathrm{WTP})$ between the scenario with the $6.5 \%$ mortgage rate and the scenario with the $4.5 \%$ mortgage rate, based on Q2 and Q3 (winsorized at - 0.3 and 0.1 in chart). Distributions are shown separately for those respondents who started with 4.5\% (in Q1 and Q2) and those who started with $6.5 \%$. Panel (b) shows trimmed means of the same variable.

(a) Distribution of effect of higher rate on $\log (\mathrm{WTP})$

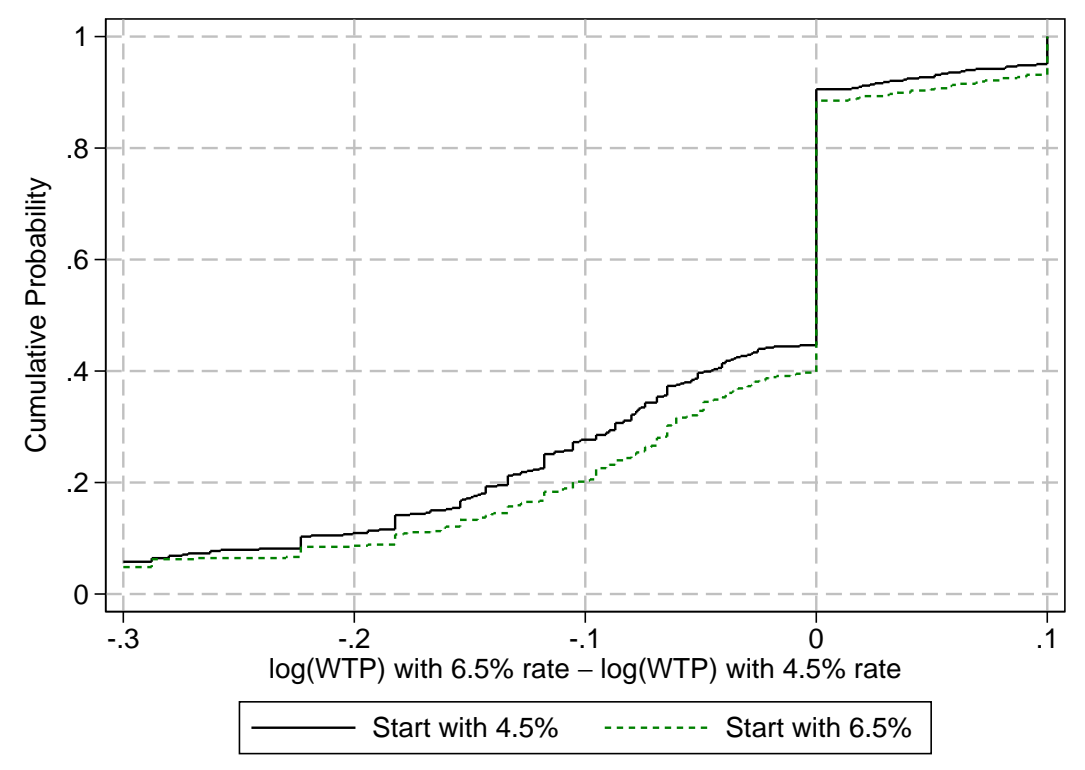

(b) Average difference between $\log ($ WTP with $r=6.5 \%)$ and $\log (\mathrm{WTP}$ with $r=4.5 \%$ )

\begin{tabular}{llllll}
\hline Sample & $\mathbf{N}$ & \multicolumn{4}{l}{ Trimmed mean without top/bottom $\mathbf{X \%}$ : } \\
\hline & & $X=0$ & $X=2.5$ & $X=5$ & $X=10$ \\
\hline Full & 962 & $-0.089^{*}$ & $-0.049^{*}$ & $-0.044^{*}$ & $-0.038^{*}$ \\
Owners & 698 & $-0.103^{*}$ & $-0.046^{*}$ & $-0.042^{*}$ & $-0.035^{*}$ \\
Renters & 264 & -0.052 & $-0.048^{*}$ & $-0.046^{*}$ & $-0.042^{*}$ \\
Start with 4.5\% & 466 & $-0.119^{*}$ & $-0.066^{*}$ & $-0.053^{*}$ & $-0.044^{*}$ \\
Start with 6.5\% & 496 & $-0.061^{*}$ & $-0.039^{*}$ & $-0.035^{*}$ & $-0.031^{*}$ \\
\hline
\end{tabular}

* denotes statistical significance at $p<0.05$ (two-tailed $t$-test). 
Figure 4. Effect of mortgage rate changes on down payment fraction. Panel (a) displays the within-respondent changes in down payment fractions between the scenario with the $6.5 \%$ mortgage rate and the scenario with the $4.5 \%$ mortgage rate, based on Q2 and Q3 (winsorized at -5 and 15 in chart). Distributions are shown separately for those respondents who started with 4.5\% (in Q1 and Q2) and those who started with 6.5\%. Panel (b) shows trimmed means of the same variable.

(a) Distribution of effect of higher rate on down payment fraction

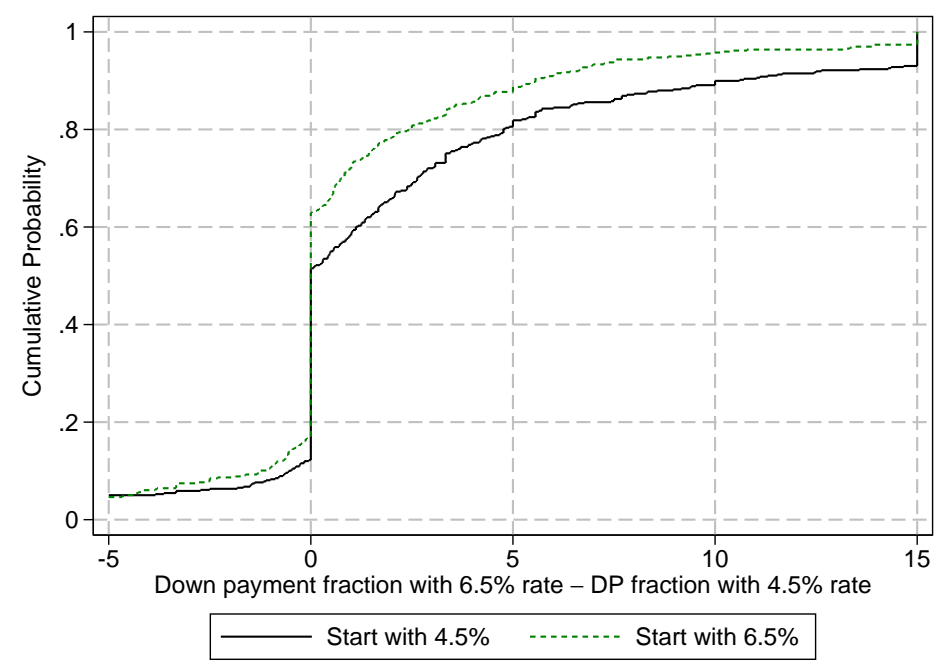

(b) Average difference between (DP fraction with $r=6.5 \%$ ) and (DP fraction with $r=4.5 \%$ )

\begin{tabular}{llllll}
\hline Sample & $\mathbf{N}$ & \multicolumn{4}{l}{ Trimmed mean without top/bottom $\mathbf{X \% :}$} \\
\hline & & $X=0$ & $X=2.5$ & $X=5$ & $X=10$ \\
\hline Full & 954 & $2.1^{*}$ & $1.6^{*}$ & $1.4^{*}$ & $1.1^{*}$ \\
Owners & 692 & $2.2^{*}$ & $1.7^{*}$ & $1.4^{*}$ & $1.1^{*}$ \\
Renters & 262 & 1.8 & $1.6^{*}$ & $1.2^{*}$ & $0.9^{*}$ \\
Start with 4.5\% & 458 & $3.1^{*}$ & $2.5^{*}$ & $2.1^{*}$ & $1.6^{*}$ \\
Start with 6.5\% & 496 & $1.1^{*}$ & $0.9^{*}$ & $0.8^{*}$ & $0.7^{*}$ \\
\hline
\end{tabular}

$*$ denotes statistical significance at $p<0.05$ (two-tailed $t$-test). 
Figure 5. Effects of $\$ \mathbf{1 0 0 , 0 0 0}$ non-housing wealth shock. Panel (a) displays the within-respondent difference in WTP and down payment (both in dollars) between Q4 and Q3 (winsorized at -10,000 and 110,000 in chart). Panel (b) shows trimmed means of the same variables, and also of the corresponding effects on $\log (\mathrm{WTP})$ and the down payment as fraction of WTP.

(a) Distribution of effect of wealth shock on WTP and down payment

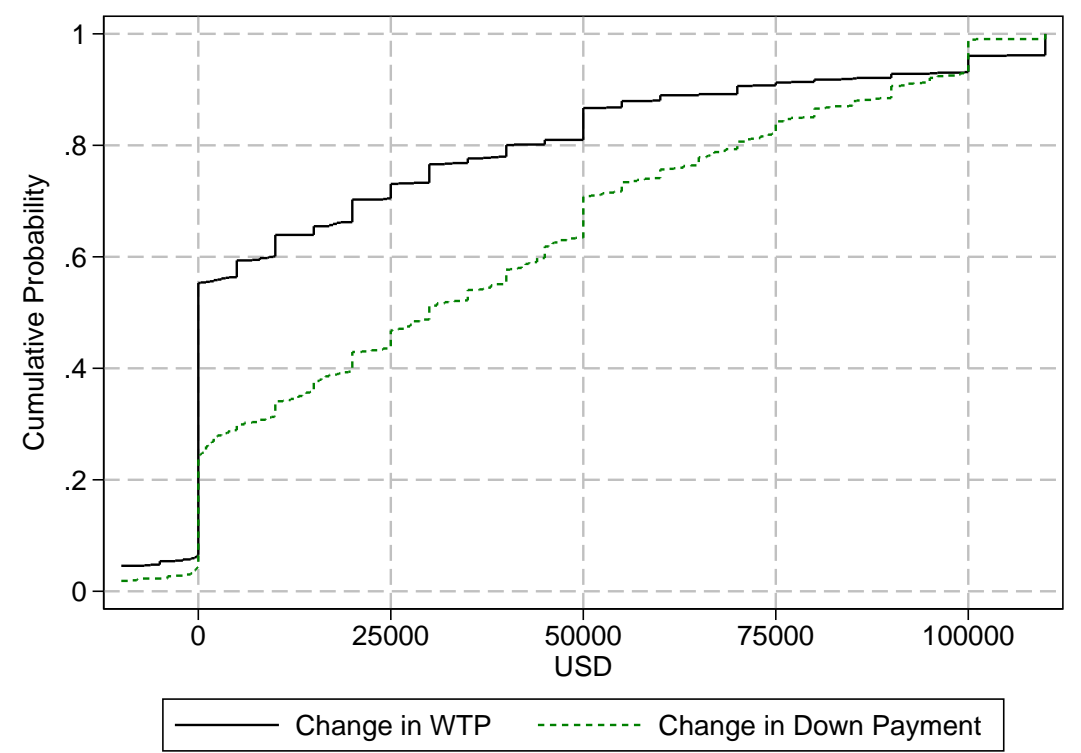

(b) Average effects on WTP and down payment

\begin{tabular}{|c|c|c|c|c|c|}
\hline \multirow[t]{2}{*}{ Sample } & \multirow[t]{2}{*}{$\mathbf{N}$} & \multicolumn{3}{|c|}{ Trimmed mean without top/bottom X\%: } & \multirow[b]{2}{*}{$X=10$} \\
\hline & & $X=0$ & $X=2.5$ & $X=5$ & \\
\hline \multicolumn{6}{|c|}{ Change in WTP, in \$: } \\
\hline Full & 962 & $11554^{*}$ & $17890^{*}$ & $17048^{*}$ & $12596^{*}$ \\
\hline Owners & 698 & $15113^{*}$ & $14925^{*}$ & $12584^{*}$ & $9420^{*}$ \\
\hline Renters & 264 & 2142 & $27808^{*}$ & $25260^{*}$ & $23134^{*}$ \\
\hline \multicolumn{6}{|c|}{ Change in $\log (W T P)$ : } \\
\hline Full & 962 & $0.173^{*}$ & $0.135^{*}$ & $0.109^{*}$ & $0.074^{*}$ \\
\hline Owners & 698 & $0.142^{*}$ & $0.085^{*}$ & $0.070^{*}$ & $0.050^{*}$ \\
\hline Renters & 264 & $0.257^{*}$ & $0.267^{*}$ & $0.249^{*}$ & $0.204^{*}$ \\
\hline \multicolumn{6}{|c|}{ Change in down payment, in $\$$ : } \\
\hline Full & 962 & $35559^{*}$ & $36547^{*}$ & $33094^{*}$ & $31367^{*}$ \\
\hline Owners & 698 & $35026^{*}$ & $36033^{*}$ & $31505^{*}$ & $30370^{*}$ \\
\hline Renters & 264 & $36966^{*}$ & $37433^{*}$ & $35695^{*}$ & $34076^{*}$ \\
\hline \multicolumn{6}{|c|}{ Change in down payment fraction (percentage points): } \\
\hline Full & 955 & $20.6^{*}$ & $20.3^{*}$ & $19.1^{*}$ & $16.3^{*}$ \\
\hline Owners & 693 & $18.0^{*}$ & $17.5^{*}$ & $16.2^{*}$ & $13.7^{*}$ \\
\hline Renters & 262 & $27.4^{*}$ & $26.5^{*}$ & $27.1^{*}$ & $24.7^{*}$ \\
\hline
\end{tabular}

* denotes statistical significance at $p<0.05$ (two-tailed $t$-test). 
Table 1: Descriptive Statistics

\begin{tabular}{lcccccc}
\hline \hline & Mean & Std. Dev. & p25 & p50 & p75 & Obs. \\
\hline Owner & 0.73 & 0.45 & 0 & 1 & 1 & 962 \\
Appraisal value (thousands) & 233.57 & 174.33 & 110 & 180 & 300 & 962 \\
Age & 47.71 & 13.25 & 36 & 49 & 59 & 962 \\
College degree or higher & 0.57 & 0.50 & 0 & 1 & 1 & 962 \\
Number correct on numeracy test & 4.03 & 1.07 & 3 & 4 & 5 & 960 \\
Willingness to take risks (1-10) & 4.29 & 2.16 & 3 & 4 & 6 & 961 \\
Married & 0.66 & 0.47 & 0 & 1 & 1 & 962 \\
Male & 0.50 & 0.50 & 0 & 1 & 1 & 962 \\
Midwest & 0.23 & 0.42 & 0 & 0 & 0 & 962 \\
Northeast & 0.20 & 0.40 & 0 & 0 & 0 & 962 \\
South & 0.33 & 0.47 & 0 & 0 & 1 & 962 \\
West & 0.23 & 0.42 & 0 & 0 & 0 & 962 \\
Single-family home & 0.73 & 0.44 & 0 & 1 & 1 & 962 \\
Apartment/Condo/Townhouse & 0.22 & 0.41 & 0 & 0 & 0 & 962 \\
E(HP growth, 1yr) & 4.07 & 5.20 & 0 & 3.13 & 6 & 919 \\
Pr(move over next 3 yrs) & 35.20 & 35.60 & 1 & 20 & 68 & 959 \\
Pr(buy | move) & 65.39 & 32.93 & 49 & 75 & 95 & 688 \\
Equity (thousands, owners only) & 134.19 & 154.43 & 30 & 84 & 185 & 695 \\
Liquid savings (thousands) & 142.94 & 264.38 & 1.5 & 15 & 175 & 940 \\
Non-housing debt (thousands) & 23.27 & 29.23 & 1.5 & 7.5 & 40 & 959 \\
Household income (thousands) & 78.56 & 50.77 & 45 & 67.5 & 125 & 952 \\
Credit score below 680 & 0.20 & 0.40 & 0 & 0 & 0 & 851 \\
Credit score 680-719 & 0.14 & 0.35 & 0 & 0 & 0 & 851 \\
Credit score 720-760 & 0.30 & 0.46 & 0 & 0 & 1 & 851 \\
Credit score above 760 & 0.35 & 0.48 & 0 & 0 & 1 & 851 \\
Time spent on these questions (minutes) & 8.49 & 4.44 & 5.4 & 7.25 & 10.4 & 962 \\
Used calculator at least once & 0.96 & 0.21 & 1 & 1 & 1 & 962 \\
Used calculator in all questions & 0.78 & 0.41 & 1 & 1 & 1 & 962 \\
\hline \hline
\end{tabular}

Note: Liquid savings, non-housing debt, and household income are elicited in ranges. To compute summary statistics, we use midpoints of these ranges, and for the top category, the lower bound. 


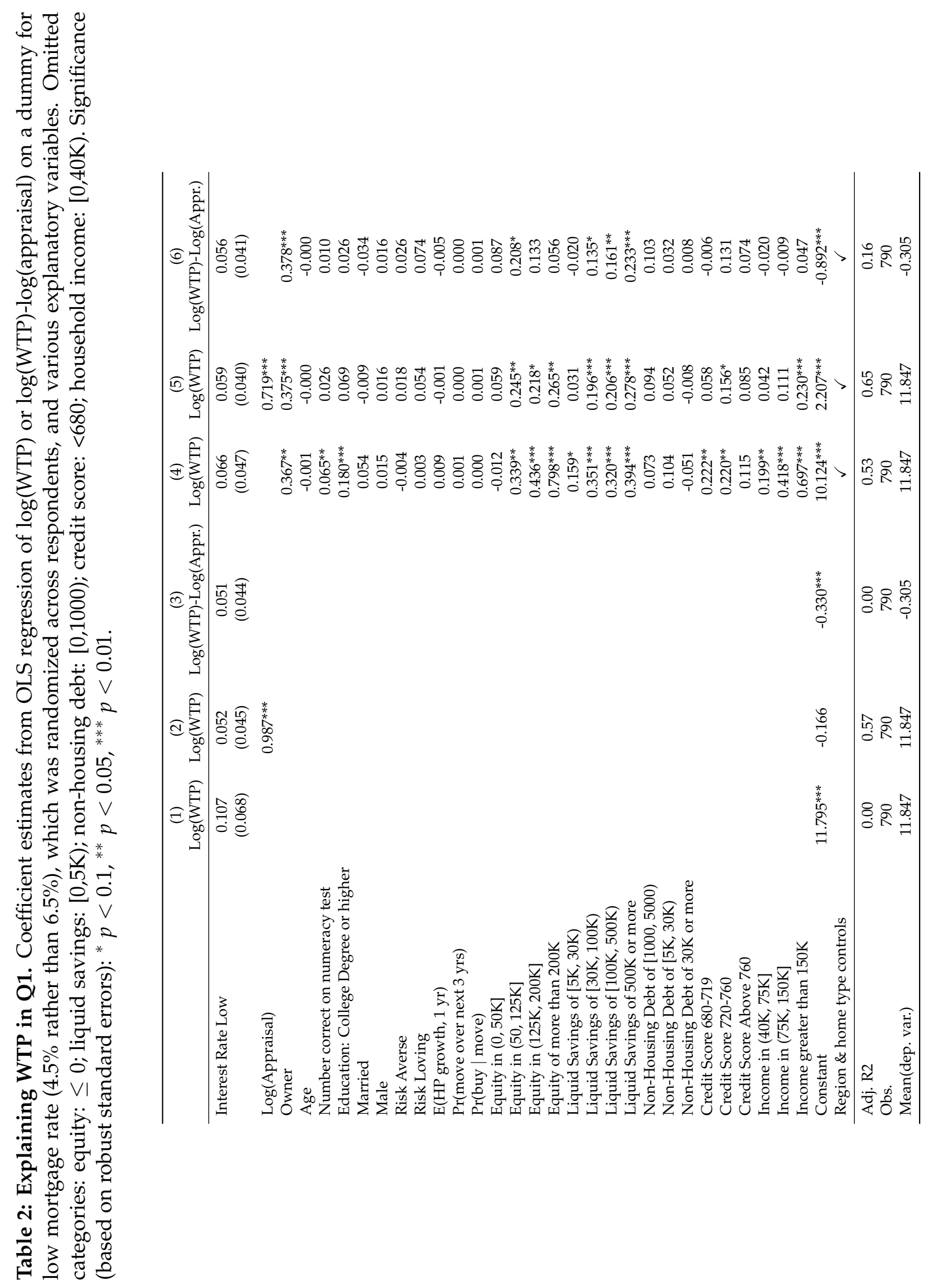


Table 3: Heterogeneity in down payment fractions in Q2. Coefficient estimates from OLS regressions; dependent variable: down payment as fraction of WTP in Q2. Significance (based on robust standard errors): ${ }^{*} p<0.1,{ }^{* *} p<0.05,{ }^{* * *} p<0.01$.

\begin{tabular}{|c|c|c|c|c|c|c|}
\hline Interest Rate Low & $-3.51^{* *}$ & $-2.97^{*}$ & $-3.23^{* *}$ & $-3.04^{*}$ & $-2.92^{*}$ & $-3.60^{* *}$ \\
\hline Owner & $-5.66^{* * *}$ & $4.73^{* *}$ & $6.53^{* * *}$ & $4.96^{* *}$ & $6.46^{* * *}$ & $-3.77^{*}$ \\
\hline Age & $0.36^{* * *}$ & $0.48^{* * *}$ & $0.59^{* * *}$ & $0.64^{* * *}$ & $0.66^{* * *}$ & $0.27^{* * *}$ \\
\hline Number correct on numeracy test & $2.27^{* * *}$ & $2.90^{* * *}$ & $3.38^{* * *}$ & $2.88^{* * *}$ & $3.56^{* * *}$ & $2.15^{* * *}$ \\
\hline Education: College Degree or higher & -1.61 & -1.12 & 0.85 & 0.40 & 1.89 & -2.07 \\
\hline Married & 0.40 & 1.21 & $3.39^{* *}$ & 2.07 & $3.81^{* *}$ & 2.13 \\
\hline Male & -0.27 & -0.34 & -0.61 & -0.57 & -0.12 & -0.68 \\
\hline Risk Averse & -0.58 & 2.11 & -0.04 & 0.20 & 0.19 & -0.18 \\
\hline Risk Loving & 1.76 & 3.42 & $4.18^{*}$ & $4.86^{*}$ & 3.69 & 2.65 \\
\hline $\mathrm{E}(\mathrm{HP}$ growth, $1 \mathrm{yr})$ & -0.08 & -0.02 & -0.06 & -0.05 & -0.08 & -0.01 \\
\hline $\operatorname{Pr}($ move over next 3 yrs $)$ & 0.03 & 0.02 & 0.02 & 0.01 & 0.02 & 0.03 \\
\hline $\operatorname{Pr}($ buy $\mid$ move $)$ & $0.08^{* * *}$ & $0.09^{* * *}$ & $0.10^{* * *}$ & $0.09^{* * *}$ & $0.11^{* * *}$ & $0.07^{* *}$ \\
\hline Equity in $(0,50 \mathrm{~K}]$ & $3.91^{* *}$ & & & & & $3.07^{*}$ \\
\hline Equity in $(50,125 \mathrm{~K}]$ & $12.17^{* * *}$ & & & & & $10.16^{* * *}$ \\
\hline Equity in $(125 \mathrm{~K}, 200 \mathrm{~K}]$ & $26.72^{* * *}$ & & & & & $23.40^{* * *}$ \\
\hline Equity of more than $200 \mathrm{~K}$ & $34.28^{* * *}$ & & & & & $30.06^{* * *}$ \\
\hline Liquid Savings of $[5 \mathrm{~K}, 30 \mathrm{~K})$ & & -1.17 & & & & $-3.55^{* *}$ \\
\hline Liquid Savings of $[30 \mathrm{~K}, 100 \mathrm{~K})$ & & 1.90 & & & & -2.33 \\
\hline Liquid Savings of $[100 \mathrm{~K}, 500 \mathrm{~K})$ & & $13.55^{* * *}$ & & & & 4.86 \\
\hline Liquid Savings of $500 \mathrm{~K}$ or more & & $17.85^{* * *}$ & & & & 4.97 \\
\hline Non-Housing Debt of $[1000,5000)$ & & & $-6.74^{* *}$ & & & -3.17 \\
\hline Non-Housing Debt of $[5 \mathrm{~K}, 30 \mathrm{~K})$ & & & $-11.43^{* * *}$ & & & $-6.02^{* * *}$ \\
\hline Non-Housing Debt of $30 \mathrm{~K}$ or more & & & $-10.42^{* * *}$ & & & $-4.20^{*}$ \\
\hline Credit Score 680-719 & & & & -0.25 & & -0.77 \\
\hline Credit Score 720-760 & & & & $4.49^{* *}$ & & 3.11 \\
\hline Credit Score Above 760 & & & & $9.70^{* * *}$ & & $5.28^{* *}$ \\
\hline Income in $(40 \mathrm{~K}, 75 \mathrm{~K}]$ & & & & & -3.15 & -3.11 \\
\hline Income in $(75 \mathrm{~K}, 150 \mathrm{~K}]$ & & & & & -4.29 & $-5.58^{* *}$ \\
\hline Income greater than $150 \mathrm{~K}$ & & & & & -0.36 & $-9.78^{* * *}$ \\
\hline Constant & $-13.37^{* *}$ & $-26.80^{* * *}$ & $-26.53^{* * *}$ & $-36.22^{* * *}$ & $-37.69^{* * *}$ & -4.31 \\
\hline Region \& home type controls & $\checkmark$ & $\checkmark$ & $\checkmark$ & $\checkmark$ & $\checkmark$ & $\checkmark$ \\
\hline Adj. R2 & 0.34 & 0.24 & 0.22 & 0.21 & 0.19 & 0.36 \\
\hline Obs. & 790 & 790 & 790 & 790 & 790 & 790 \\
\hline Mean(dep. var.) & 22.96 & 22.96 & 22.96 & 22.96 & 22.96 & 22.96 \\
\hline
\end{tabular}


Table 4: Heterogeneity in the effect of the lower down payment requirement on WTP. Coefficient estimates from OLS regressions; dependent variable: $\log \left(\mathrm{WTP}_{\mathrm{Q} 2}\right)-\log \left(\mathrm{WTP}_{\mathrm{Q} 1}\right)$. Significance (based on robust standard errors): ${ }^{*} p<0.1,{ }^{* *} p<0.05,{ }^{* * *} p<0.01$.

\begin{tabular}{|c|c|c|c|c|c|c|}
\hline Interest Rate Low & $-0.059^{* *}$ & $-0.056^{* *}$ & $-0.055^{*}$ & $-0.053^{*}$ & $-0.053^{*}$ & $-0.059^{* *}$ \\
\hline Owner & $-0.144^{*}$ & $-0.277^{* * *}$ & $-0.292^{* * *}$ & $-0.266^{* * *}$ & $-0.279^{* * *}$ & $-0.149^{*}$ \\
\hline Age & $-0.002^{* *}$ & $-0.002 *$ & $-0.003^{* *}$ & $-0.003^{* * *}$ & $-0.003^{* * *}$ & -0.002 \\
\hline Number correct on numeracy test & -0.021 & -0.016 & -0.020 & -0.014 & -0.019 & -0.017 \\
\hline Education: College Degree or higher & -0.042 & -0.028 & -0.044 & -0.033 & -0.031 & -0.021 \\
\hline Married & $0.090^{* * *}$ & $0.091^{* * *}$ & $0.076^{* *}$ & $0.088^{* * *}$ & $0.097^{* * *}$ & $0.102^{* * *}$ \\
\hline Male & 0.017 & 0.021 & 0.019 & 0.024 & 0.018 & 0.030 \\
\hline Risk Averse & 0.026 & 0.011 & 0.022 & 0.023 & 0.017 & 0.020 \\
\hline Risk Loving & 0.012 & 0.001 & 0.002 & -0.008 & 0.008 & 0.004 \\
\hline $\mathrm{E}(\mathrm{HP}$ growth, 1 yr) & -0.000 & -0.001 & -0.001 & -0.001 & -0.000 & -0.001 \\
\hline $\operatorname{Pr}($ move over next 3 yrs) & 0.000 & 0.001 & 0.001 & 0.001 & 0.001 & 0.000 \\
\hline $\operatorname{Pr}($ buy $\mid$ move $)$ & 0.001 & 0.001 & 0.001 & 0.001 & 0.001 & 0.001 \\
\hline Equity in $(0,50 \mathrm{~K}]$ & $-0.118^{*}$ & & & & & -0.101 \\
\hline Equity in $(50,125 \mathrm{~K}]$ & $-0.237^{* * *}$ & & & & & $-0.197^{* * *}$ \\
\hline Equity in $(125 \mathrm{~K}, 200 \mathrm{~K}]$ & $-0.189^{* *}$ & & & & & $-0.131^{*}$ \\
\hline Equity of more than $200 \mathrm{~K}$ & $-0.194^{* * *}$ & & & & & $-0.148^{*}$ \\
\hline Liquid Savings of $[5 \mathrm{~K}, 30 \mathrm{~K})$ & & 0.020 & & & & 0.056 \\
\hline Liquid Savings of $[30 \mathrm{~K}, 100 \mathrm{~K})$ & & $-0.091^{* *}$ & & & & -0.042 \\
\hline Liquid Savings of $[100 \mathrm{~K}, 500 \mathrm{~K})$ & & $-0.092^{* *}$ & & & & -0.026 \\
\hline Liquid Savings of $500 \mathrm{~K}$ or more & & $-0.077^{*}$ & & & & -0.012 \\
\hline Non-Housing Debt of $[1000,5000)$ & & & -0.002 & & & -0.007 \\
\hline Non-Housing Debt of $[5 \mathrm{~K}, 30 \mathrm{~K})$ & & & 0.030 & & & 0.012 \\
\hline Non-Housing Debt of $30 \mathrm{~K}$ or more & & & 0.045 & & & 0.026 \\
\hline Credit Score 680-719 & & & & -0.078 & & -0.082 \\
\hline Credit Score 720-760 & & & & $-0.135^{* *}$ & & $-0.112^{*}$ \\
\hline Credit Score Above 760 & & & & $-0.123^{* *}$ & & -0.079 \\
\hline in $(40 \mathrm{~K}, 75 \mathrm{~K}]$ & & & & & -0.016 & -0.001 \\
\hline Inco & & & & & -0.041 & -0.020 \\
\hline than $150 \mathrm{~K}$ & & & & & $-0.094^{*}$ & -0.053 \\
\hline it & $0.505^{* * *}$ & $0.472^{* * *}$ & $0.495^{* * *}$ & $0.547^{* * *}$ & $0.520^{* * *}$ & $0.496^{* * *}$ \\
\hline Region \& home type controls & $\checkmark$ & $\checkmark$ & $\checkmark$ & $\checkmark$ & $\checkmark$ & $\checkmark$ \\
\hline Adj. R2 & 0.11 & 0.11 & 0.10 & 0.11 & 0.10 & 0.11 \\
\hline Obs. & 790 & 790 & 790 & 790 & 790 & 790 \\
\hline Mean(dep. var.) & 0.161 & 0.161 & 0.161 & 0.161 & 0.161 & 0.161 \\
\hline
\end{tabular}


Table 5: Heterogeneity in the effect of the change in rates on WTP. Coefficient estimates from OLS regressions; dependent variable: $\log (\mathrm{WTP} \mid 6.5 \%)-\log (\mathrm{WTP} \mid 4.5 \%)$. Significance (based on robust standard errors): ${ }^{*} p<0.1,{ }^{* *} p<0.05,{ }^{* * *} p<0.01$.

\begin{tabular}{|c|c|c|c|c|c|c|}
\hline Starting Interest Rate Low & -0.008 & -0.008 & -0.008 & -0.007 & -0.007 & -0.008 \\
\hline DP Frac. in Q2 (0-1) & 0.016 & $0.026^{* *}$ & $0.028^{* *}$ & $0.029^{* *}$ & $0.025^{* *}$ & 0.017 \\
\hline Owner & 0.023 & $0.031^{* *}$ & $0.031^{* *}$ & $0.033^{* *}$ & $0.032^{* *}$ & 0.025 \\
\hline Age & 0.000 & 0.000 & 0.000 & 0.000 & 0.000 & 0.000 \\
\hline Number correct on numeracy test & -0.004 & -0.004 & -0.003 & -0.003 & -0.003 & -0.003 \\
\hline Education: College Degree or higher & $-0.013^{*}$ & -0.012 & -0.011 & -0.009 & -0.010 & -0.011 \\
\hline Married & 0.001 & 0.001 & 0.002 & 0.003 & 0.004 & 0.005 \\
\hline Male & $0.018^{* *}$ & $0.018^{* *}$ & $0.018^{* *}$ & $0.018^{* *}$ & $0.018^{* *}$ & $0.018^{* *}$ \\
\hline Risk Averse & -0.007 & -0.005 & -0.004 & -0.006 & -0.007 & -0.007 \\
\hline Risk Loving & 0.008 & 0.009 & 0.010 & 0.008 & 0.008 & 0.008 \\
\hline $\mathrm{E}(\mathrm{HP}$ growth, $1 \mathrm{yr})$ & -0.002 & -0.002 & $-0.002^{*}$ & -0.002 & -0.002 & -0.002 \\
\hline $\operatorname{Pr}($ move over next 3 yrs) & 0.000 & 0.000 & 0.000 & 0.000 & 0.000 & 0.000 \\
\hline $\operatorname{Pr}($ buy $\mid$ move) & -0.000 & -0.000 & -0.000 & -0.000 & -0.000 & -0.000 \\
\hline Equity in $(0,50 \mathrm{~K}]$ & 0.010 & & & & & 0.010 \\
\hline Equity in $(50,125 \mathrm{~K}]$ & -0.006 & & & & & -0.005 \\
\hline Equity in $(125 \mathrm{~K}, 200 \mathrm{~K}]$ & 0.018 & & & & & 0.023 \\
\hline Equity of more tha & 0.021 & & & & & 0.020 \\
\hline Liquid Savings of $[5 \mathrm{~K}, 30 \mathrm{~K})$ & & 0.001 & & & & 0.004 \\
\hline Liquid Savings of $[30 \mathrm{~K}, 100 \mathrm{~K})$ & & -0.001 & & & & 0.003 \\
\hline Liquid Savings of [100K, 500K) & & -0.005 & & & & -0.001 \\
\hline Liquid Savings of $500 \mathrm{~K}$ or $\mathrm{r}$ & & 0.011 & & & & 0.011 \\
\hline Non-Housing Debt of $[1000,5000)$ & & & 0.016 & & & 0.018 \\
\hline Non-Housing Debt of $[5 \mathrm{~K}, 30 \mathrm{~K})$ & & & -0.002 & & & -0.001 \\
\hline Debt of $30 \mathrm{~K}$ or more & & & 0.010 & & & 0.012 \\
\hline Credit Scor & & & & -0.015 & & -0.015 \\
\hline Credit & & & & -0.004 & & -0.005 \\
\hline Cred & & & & -0.018 & & -0.016 \\
\hline Incor & & & & & -0.007 & -0.007 \\
\hline Inco & & & & & -0.012 & -0.011 \\
\hline Inco & & & & & -0.003 & -0.004 \\
\hline Consta & $-0.064^{* *}$ & $-0.073^{* *}$ & $-0.085^{* * *}$ & $-0.077^{* * *}$ & $-0.074^{* *}$ & $-0.068^{* *}$ \\
\hline Region \& home type controls & $\checkmark$ & $\checkmark$ & $\checkmark$ & $\checkmark$ & $\checkmark$ & $\checkmark$ \\
\hline & 0.03 & 0.02 & 0.03 & 0.03 & 0.03 & 0.03 \\
\hline Obs. & 790 & 790 & 790 & 790 & 790 & 790 \\
\hline Mean(dep. var.) & -0.051 & -0.051 & -0.051 & -0.051 & -0.051 & -0.051 \\
\hline
\end{tabular}


Table 6: Heterogeneity in the effect of $\mathbf{\$ 1 0 0 , 0 0 0}$ wealth shock on WTP. Coefficient estimates from OLS regressions; dependent variable: $\log \left(\mathrm{WTP}_{\mathrm{Q} 4}\right)-\log \left(\mathrm{WTP}_{\mathrm{Q} 3}\right)$. Significance (based on robust standard errors): ${ }^{*} p<0.1,{ }^{* *} p<0.05,{ }^{* * *} p<0.01$.

\begin{tabular}{|c|c|c|c|c|c|c|}
\hline Interest Rate Low & 0.013 & 0.016 & 0.015 & 0.014 & 0.014 & 0.015 \\
\hline Owner & $-0.108^{*}$ & $-0.110^{* * *}$ & $-0.124^{* * *}$ & $-0.111^{* * *}$ & $-0.111^{* * *}$ & $-0.116^{* *}$ \\
\hline Age & -0.001 & -0.001 & -0.001 & -0.001 & $-0.001^{*}$ & -0.000 \\
\hline Number correct on numeracy test & 0.001 & 0.003 & 0.001 & 0.003 & 0.000 & 0.007 \\
\hline Education: College Degree or higher & 0.008 & 0.015 & -0.000 & 0.009 & 0.013 & 0.023 \\
\hline Married & $-0.077^{* * *}$ & $-0.074^{* * *}$ & $-0.084^{* * *}$ & $-0.079^{* * *}$ & $-0.068^{* *}$ & $-0.063^{* *}$ \\
\hline Male & 0.019 & 0.022 & 0.021 & 0.021 & 0.020 & 0.025 \\
\hline Risk Averse & -0.016 & -0.024 & -0.014 & -0.013 & -0.019 & -0.019 \\
\hline Risk Loving & -0.016 & -0.020 & -0.019 & -0.026 & -0.016 & -0.019 \\
\hline $\mathrm{E}(\mathrm{HP}$ growth, $1 \mathrm{yr})$ & $0.004^{* *}$ & $0.004^{*}$ & $0.004^{*}$ & $0.004^{*}$ & $0.004^{* *}$ & $0.004^{*}$ \\
\hline $\operatorname{Pr}($ move over next 3 yrs $)$ & -0.000 & -0.000 & -0.000 & -0.000 & -0.000 & -0.000 \\
\hline $\operatorname{Pr}($ buy $\mid$ move $)$ & -0.001 & -0.001 & -0.001 & -0.001 & -0.001 & -0.000 \\
\hline Equity in $(0,50 \mathrm{~K}]$ & 0.011 & & & & & 0.023 \\
\hline Equity in $(50,125 \mathrm{~K}]$ & -0.018 & & & & & 0.012 \\
\hline Equity in $(125 \mathrm{~K}, 200 \mathrm{~K}]$ & -0.047 & & & & & -0.006 \\
\hline Equity of more than $200 \mathrm{~K}$ & -0.056 & & & & & -0.010 \\
\hline Liquid Savings of $[5 \mathrm{~K}, 30 \mathrm{~K})$ & & 0.001 & & & & 0.008 \\
\hline Liquid Savings of $[30 \mathrm{~K}, 100 \mathrm{~K})$ & & $-0.056^{* *}$ & & & & -0.038 \\
\hline Liquid Savings of $[100 \mathrm{~K}, 500 \mathrm{~K})$ & & $-0.075^{* * *}$ & & & & $-0.046^{*}$ \\
\hline Liquid Savings of $500 \mathrm{~K}$ or more & & $-0.071^{* *}$ & & & & -0.043 \\
\hline Non-Housing Debt of $[1000,5000)$ & & & 0.028 & & & 0.015 \\
\hline Non-Housing Debt of $[5 \mathrm{~K}, 30 \mathrm{~K})$ & & & 0.009 & & & -0.010 \\
\hline Non-Housing Debt of $30 \mathrm{~K}$ or more & & & $0.052^{* *}$ & & & 0.032 \\
\hline Credit Score 680-719 & & & & -0.042 & & -0.045 \\
\hline Credit Score 720-760 & & & & -0.053 & & -0.042 \\
\hline Credit Score Above 760 & & & & $-0.066^{* *}$ & & -0.039 \\
\hline Income in $(40 \mathrm{~K}, 75 \mathrm{~K}]$ & & & & & -0.016 & -0.015 \\
\hline Incor & & & & & -0.036 & -0.029 \\
\hline Incom & & & & & $-0.074^{* *}$ & -0.050 \\
\hline Constant & $0.321^{* * *}$ & $0.320^{* * *}$ & $0.332^{* * *}$ & $0.372^{* * *}$ & $0.363^{* * *}$ & $0.299^{* * *}$ \\
\hline Region \& home type controls & $\checkmark$ & $\checkmark$ & $\checkmark$ & $\checkmark$ & $\checkmark$ & $\checkmark$ \\
\hline Adj. R2 & 0.09 & 0.10 & 0.10 & 0.10 & 0.09 & 0.10 \\
\hline Obs. & 790 & 790 & 790 & 790 & 790 & 790 \\
\hline Mean(dep. var.) & 0.120 & 0.120 & 0.120 & 0.120 & 0.120 & 0.120 \\
\hline
\end{tabular}


Table 7: Effect of mortgage rate changes on WTP - subsamples. Table shows average difference between $\log ($ WTP with $r=6.5 \%)$ and $\log$ (WTP with $r=4.5 \%$ ) for different subsamples, trimming $2.5 \%$ or $5 \%$ of extreme observations, as in panel (b) of Figure 3. Final column shows proportion of respondents in sample that do not adjust WTP between Q2 and Q3.

\begin{tabular}{lllll}
\hline Sample & $\mathbf{N}$ & \multicolumn{2}{c}{ Trimmed means } & \% with no change \\
& & $X=2.5$ & $X=5$ & \\
\hline Full & 962 & $-0.049^{*}$ & $-0.044^{*}$ & 47.4 \\
Used calculator in Q3 & 831 & $-0.055^{*}$ & $-0.049^{*}$ & 43.6 \\
Used calculator in all questions & 754 & $-0.053^{*}$ & $-0.045^{*}$ & 44.2 \\
Time spent on Q3 > median & 476 & $-0.058^{*}$ & $-0.050^{*}$ & 41.4 \\
Change WTP or DP in Q4 & 800 & $-0.053^{*}$ & $-0.049^{*}$ & 43.1 \\
WTP in Q2 $\neq$ appraisal & 828 & $-0.053^{*}$ & $-0.047^{*}$ & 45.2 \\
All of the above & 317 & $-0.053^{*}$ & $-0.047^{*}$ & 36.9 \\
\hline
\end{tabular}

${ }^{*}$ denotes statistical significance at $p<0.05$ (two-tailed $t$-test). 
Table 8: Effect of house price expectations Table shows effects on two measures of expected house price growth on $\log (\mathrm{WTP})$ in Q1 (panel (a)) and the self-reported estimated value of the respondents' home (panel (b)). "Other controls" include all the controls from Table 2. Significance (based on robust standard errors): ${ }^{*} p<0.1,{ }^{* *} p<0.05,{ }^{* * *} p<0.01$.

(a) Dependent variable: $\log \left(\mathrm{WTP}_{\mathrm{Q} 1}\right)$

\begin{tabular}{lcccccc}
\hline \hline & $(1)$ & $(2)$ & $(3)$ & $(4)$ & $(5)$ & $(6)$ \\
\hline E(HP growth, 1 yr) & 0.001 & 0.009 & -0.001 & & & \\
& $(0.008)$ & $(0.006)$ & $(0.005)$ & & & \\
Property in zip is & & & & $0.222^{* * *}$ & $0.098^{*}$ & 0.024 \\
good investment & & & & $(0.069)$ & $(0.050)$ & $(0.044)$ \\
Controls for log(appraisal) & No & No & Yes & No & No & Yes \\
Other controls & No & Yes & Yes & No & Yes & Yes \\
Obs. & 790 & 790 & 790 & 790 & 790 & 790 \\
Mean(dep. var.) & 11.847 & 11.847 & 11.847 & 11.847 & 11.847 & 11.847 \\
\hline \hline
\end{tabular}

(b) Dependent variable: $\log ($ appraisal)

\begin{tabular}{lcccc}
\hline \hline & $(1)$ & $(2)$ & $(3)$ & $(4)$ \\
\hline E(HP growth, 1 yr) & $0.013^{* *}$ & $0.013^{* * *}$ & & \\
& $(0.006)$ & $(0.004)$ & & \\
Property in zip is & & & $0.237^{* * *}$ & $0.102^{* * *}$ \\
good investment & & & $(0.053)$ & $(0.035)$ \\
Other controls & No & Yes & No & Yes \\
Obs. & 790 & 790 & 790 & 790 \\
Mean(dep. var.) & 12.152 & 12.152 & 12.152 & 12.152 \\
\hline \hline
\end{tabular}




\section{Appendix}

\section{A Screenshots from survey $(\mathrm{Q} 1-\mathrm{Q} 4)$}

The questions in the screenshots shown here are for current owners; instructions given to current renters (available upon request) did not mention that respondents would sell their current residence and pay off their mortgage (since they did not own their residence).

Suppose that you were to sell your current primary residence today and pay off your outstanding mortgage. Further, suppose you were to move to a town/city similar to your current one. You want to buy a home, as you intend to stay for the indefinite future.

You have found a home that you like, and are planning to put in an offer on the house. Homes similar to the one that you are interested in have been selling for $\$ 230,000$ lately.

You need to think about the maximum amount you would be willing to pay for the home, taking into account how much of a down payment you would be able to make.

Assume that you are required to make a down payment of $20 \%$ of the purchase price, and finance the rest with a 30 -year fixed-rate mortgage with an interest rate of $6.5 \%$.

The table below shows two examples of what different purchase prices would mean for your effective total monthly payment (including maintenance costs, property taxes and insurance, and taking into account the tax deductibility of interest payments).

\begin{tabular}{|c|c|c|c|}
\hline Purchase Price & $\begin{array}{c}\text { Down Payment } \\
(20 \%)\end{array}$ & Mortgage & $\begin{array}{c}\text { Effective Monthly } \\
\text { Payment }\end{array}$ \\
\hline$\$ 290,000$ & $\$ 58,000$ & $\$ 232,000$ & $\$ 1,703$ \\
\hline$\$ 170,000$ & $\$ 34,000$ & $\$ 136,000$ & $\$ 1,264$ \\
\hline
\end{tabular}

For instance, if you were to pay $\$ 290,000$ for the house, with a required down payment of $\$ 58,000$, your monthly payment would be $\$ 1,703$. On the other hand, if you paid $\$ 170,000$, with the required down payment of $\$ 34,000$, your monthly payment would be $\$ 1,264$.

\section{CALCULATOR}

Below is a tool you can use to determine what your down payment and monthly payment would be based on different purchase prices. You can put in any purchase price, and see what it means for your required down payment and your effective monthly payment. You can use this calculator as many times as you would like to help you arrive at the maximum amount you would pay for this home. You will enter your final answers at the bottom of the page.

Purchase Price: $\$ \quad 250000$

\begin{tabular}{|c|c|c|c|}
\hline Purchase Price & Down Payment & Mortgage & $\begin{array}{c}\text { Effective Monthly } \\
\text { Payment }\end{array}$ \\
\hline$\$ 250,000$ & $\$ 50,000$ & $\$ 200,000$ & $\$ 1,556$ \\
\hline
\end{tabular}

FINAL ANSWER

What would be the maximum amount you would be willing and able to pay for this home today?

Note that you need to be able to make a down payment of $20 \%$ of the purchase price that you enter, so pick a purchase price taking into account your financial situation if you were to sell your current home (and pay off your outstanding mortgage) today.

\section{$\$ 240000$}

You stated that you would be willing to pay $\$ 240,000$ for this home. This would mean you would be required to make a down payment of $\$ 48,000$ and that your monthly payment would be $\$ 1,520$ per month. If you are not satisfied with this, please change your answer, otherwise click next.

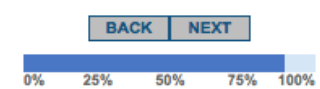


Consider the same situation as before, where you are planning to put an offer on a home that you like. As before, homes similar to the one that you are interested in have been selling for $\$ 230,000$ lately.

You need to think about the maximum amount you would be willing to pay for the home, taking into account how much of a down payment you would be able to make.

Now, the minimum down payment is only $5 \%$ instead of a required $20 \%$ of the purchase price. However, you also have a choice of putting down more than $5 \%$ of the purchase price, if you wish (and have the financial resources to do so - after selling your current home). As before, the mortgage interest rate is $\underline{6.5 \%}$.

So now you have to choose both the maximum price that you are willing to pay for the home, as well as the down payment (which cannot be less than $5 \%$ of the purchase price). The table below shows some examples of what different purchase prices would mean for your effective total monthly payment (including maintenance costs, property taxes and insurance, and taking into account the tax deductibility of interest payments) if you made only the minimum down payment of $5 \%$.

\begin{tabular}{|c|c|c|c|}
\hline Purchase Price & $\begin{array}{c}\text { Down Payment } \\
(5 \%)\end{array}$ & Mortgage & $\begin{array}{c}\text { Effective Monthly } \\
\text { Payment }\end{array}$ \\
\hline$\$ 240,000$ & $\$ 12,000$ & $\$ 228,000$ & $\$ 1,684$ \\
\hline$\$ 300,000$ & $\$ 15,000$ & $\$ 285,000$ & $\$ 1,945$ \\
\hline$\$ 180,000$ & $\$ 9,000$ & $\$ 171,000$ & $\$ 1,424$ \\
\hline
\end{tabular}

Instead if you were to make a down payment greater than the minimum, say $20 \%$ of the purchase price, the different purchase prices listed in the table above would now imply the following for your total monthly payment.

\begin{tabular}{|c|c|c|c|}
\hline Purchase Price & $\begin{array}{c}\text { Down Payment } \\
(20 \%)\end{array}$ & Mortgage & $\begin{array}{c}\text { Effective Monthly } \\
\text { Payment }\end{array}$ \\
\hline$\$ 240,000$ & $\$ 48,000$ & $\$ 192,000$ & $\$ 1,520$ \\
\hline$\$ 300,000$ & $\$ 60,000$ & $\$ 240,000$ & $\$ 1,739$ \\
\hline$\$ 180,000$ & $\$ 36,000$ & $\$ 144,000$ & $\$ 1,300$ \\
\hline
\end{tabular}

In the previous scenario, you chose a purchase price of $\$ 240,000$ with a required down payment of $\$ 48,000$, resulting in a monthly mortgage payment of $\$ 1,520$.

CALCULATOR

Below is a tool you can use to determine what your monthly payment would be based on different purchase prices and down payments. You can put in any purchase price and any down payment (which has to be at least $5 \%$ of the purchase price but can be any amount above that), and see what it means for your effective monthly payment. You can use this calculator as many times as you would like to help you arrive at the maximum amount you would pay for this home. You will enter your final answers at the bottom of the page.

Purchase Price: \$275000

Down Payment: \$ 25000

\begin{tabular}{|c|c|c|c|}
\hline Purchase Price & Down Payment & Mortgage & $\begin{array}{c}\text { Effective Monthly } \\
\text { Payment }\end{array}$ \\
\hline $\mathbf{\$ 2 7 5 , 0 0 0}$ & $\$ 25,000$ & $\$ 250,000$ & $\$ 1,785$ \\
\hline
\end{tabular}

FINAL ANSWER

What would be the maximum purchase price you would be willing and able to pay for this home today?

Note that you need to be able to make a down payment of at least $5 \%$ of the purchase price that you enter, so pick a purchase price taking into account your financial situation if you were to sell your current home (and pay off your outstanding mortgage) today.

$\$ 250000$

And how high would your down payment be? Your down payment must be $\$ 12,500$ or more.

$\$ 25000$

You stated that you would be willing to pay $\$ 250,000$ for this home, and put a down payment of $\$ 25,000$. This would mean that your monthly payment would be $\$ 1,671$ per month. If you are not satisfied with this, please change your answer, otherwise click next. 
Consider the same situation as before, where you are planning to put an offer on a home that you like. As before, homes similar to the one that you are interested in have been selling for $\$ 230,000$ lately.

Assume now that mortgage interest rate is $4.5 \%$ instead of $6.5 \%$. For the purchase price and down payment as on the previous page, that would mean a monthly payment of $\$ 1,510$ instead of $\$ 1,671$.

You need to think about how this change affects the maximum amount you would be willing to pay for the home. You still need to make a down payment of at least $5 \%$ (and can put down more than that if you wish, and have the financial resources to do so - after selling your current home).

The table below shows some examples of what different purchase prices would mean for your effective total monthly payment if you made only the minimum down payment of $\underline{5 \%}$

\begin{tabular}{|c|c|c|c|}
\hline Purchase Price & $\begin{array}{c}\text { Down Payment } \\
(5 \%)\end{array}$ & Mortgage & $\begin{array}{c}\text { Effective Monthly } \\
\text { Payment }\end{array}$ \\
\hline $\mathbf{\$ 2 5 0 , 0 0 0}$ & $\$ 12,500$ & $\$ 237,500$ & $\$ 1,558$ \\
\hline$\$ 310,000$ & $\$ 15,500$ & $\$ 294,500$ & $\$ 1,778$ \\
\hline$\$ 190,000$ & $\$ 9,500$ & $\$ 180,500$ & $\$ 1,338$ \\
\hline
\end{tabular}

Instead if you were to make a down payment greater than the minimum, say $20 \%$ of the purchase price, the different purchase prices listed in the table above would now imply the following for your total monthly payment.

\begin{tabular}{|c|c|c|c|}
\hline Purchase Price & $\begin{array}{c}\text { Down Payment } \\
(20 \%)\end{array}$ & Mortgage & $\begin{array}{c}\text { Effective Monthly } \\
\text { Payment }\end{array}$ \\
\hline$\$ 250,000$ & $\$ 50,000$ & $\$ 200,000$ & $\$ 1,413$ \\
\hline$\$ 310,000$ & $\$ 62,000$ & $\$ 248,000$ & $\$ 1,598$ \\
\hline$\$ 190,000$ & $\$ 38,000$ & $\$ 152,000$ & $\$ 1,228$ \\
\hline
\end{tabular}

How would the decrease in the interest rate affect both the maximum amount and down payment you are willing to pay? In the previous scenario, you chose a purchase price of $\$ 250,000$ and a down payment of $\$ 25,000$.

CALCULATOR

Below is a tool you can use to determine what your monthly payment would be based on different purchase prices and down payments. You can put in any purchase price and any down payment (which has to be at least $5 \%$ of the purchase price but can be any amount above that), and see what it means for your effective monthly payment. You can use this calculator as many times as you would like to help you arrive at the maximum amount you would pay for this home. You will enter your final answers at the bottom of the page.

Purchase Price: $\$ 260000$

Down Payment: \$ 15000

\begin{tabular}{|c|c|c|c|}
\hline Purchase Price & Down Payment & Mortgage & $\begin{array}{c}\text { Effective Monthly } \\
\text { Payment }\end{array}$ \\
\hline $\mathbf{\$ 2 6 0 , 0 0 0}$ & $\$ 15,000$ & $\$ 245,000$ & $\$ 1,587$ \\
\hline
\end{tabular}

\section{FINAL ANSWER}

What would be the maximum purchase price you would be willing and able to pay for this home today?

Note that you need to be able to make a down payment of at least $5 \%$ of the purchase price that you enter, so pick a purchase price taking into account your financial situation if you were to sell your current home (and pay off your outstanding mortgage) today.

$\$ 265000$

And how high would your down payment be? Your down payment can be $\$ 13,250$ or more.

$\$ 20000$

You stated that you would be willing to pay $\$ 265,000$ for this home, and put a down payment of $\$ 20,000$. This would mean that your monthly payment would be $\$ 1,587$ per month. If you are not satisfied with this, please change your answer, otherwise click next. 
We return to scenario that you just answered, with a minimum down payment of $5 \%$ and a mortgage interest rate of $4.5 \%$. You said that you would be willing to pay $\$ 265,000$ for the home, and put a down payment of $\$ 20,000$, leading to an effective monthly payment of $\$ 1,587$.

Suppose now that you just inherited $\$ 100,000$ in cash. You could use all or part of this towards the down payment if you want but you don't have to. How would this affect your maximum price and down payment for the same home that you considered in the previous three scenarios?

CALCULATOR

Below is a tool you can use to determine what your monthly payment would be based on different purchase prices and down payments. You can put in any purchase price and any down payment (which has to be at least $5 \%$ of the purchase price but can be any amount above that), and see what it means for your effective monthly payment. You can use this calculator as many times as you would like to help you arrive at the maximum amount you would pay for this home. You will enter your final answers at the bottom of the page.

Purchase Price: $\$ \quad 275000$

Down Payment: \$ 40000

\begin{tabular}{|c|c|c|c|}
\hline Purchase Price & Down Payment & Mortgage & $\begin{array}{c}\text { Effective Monthly } \\
\text { Payment }\end{array}$ \\
\hline $\mathbf{\$ 2 7 5 , 0 0 0}$ & $\$ 40,000$ & $\$ 235,000$ & $\$ 1,548$ \\
\hline
\end{tabular}

FINAL ANSWER

What would be the maximum purchase price you would be willing and able to pay for this home today?

Note that you need to be able to make a down payment of at least $5 \%$ of the purchase price that you enter. So pick a purchase price taking into account your financial situation if you were to sell your current home today, and the fact that you now have an additional $\$ 100,000$.

$\$ 280000$

And how high would your down payment be? Your down payment can be $\$ 14,000$ or more.

$\$ 60000$

You stated that you would be willing to pay $\$ 280,000$ for this home, and put a down payment of $\$ 60,000$. This would mean that your monthly payment would be $\$ 1,490$ per month. If you are not satisfied with this, please change your answer, otherwise click next.

๑2014 nielsen | 区

\begin{tabular}{|l|l|}
\hline BACK & NEXT \\
\hline
\end{tabular}

\begin{tabular}{lllll}
\hline $0 \%$ & $25 \%$ & $50 \%$ & $75 \%$ & $100 \%$
\end{tabular}




\section{B Additional tables}

Table A-1: WTP in Q1 - robustness. Table shows alternative specifications for columns 5 and 6 of Table 2. Significance (based on robust standard errors): ${ }^{*} p<0.1,{ }^{* *} p<0.05,{ }^{* * *} p<0.01$.

\begin{tabular}{|c|c|c|c|c|c|c|}
\hline \multicolumn{7}{|l|}{ A. $\log (\mathrm{WTP})$} \\
\hline Interest Rate Low & 0.059 & 0.050 & 0.053 & 0.049 & 0.046 & 0.046 \\
\hline $\log$ (Appr.) & $0.719^{* * *}$ & $0.802^{* * *}$ & $0.792^{* * *}$ & $0.859^{* * *}$ & $0.842^{* * *}$ & $0.805^{* * *}$ \\
\hline Equity in $(0,50 \mathrm{~K}]$ & 0.059 & 0.111 & & & & \\
\hline Equity in $(50,125 \mathrm{~K}]$ & $0.245^{* *}$ & $0.334^{* * *}$ & & & & \\
\hline Equity in $(125 \mathrm{~K}, 200 \mathrm{~K}]$ & $0.218^{*}$ & $0.332^{* * *}$ & & & & \\
\hline Equity of more than $200 \mathrm{~K}$ & $0.265^{* *}$ & $0.352^{* * *}$ & & & & \\
\hline Liquid Savings of [5K, 30K) & 0.031 & & 0.070 & & & \\
\hline Liquid Savings of [30K, 100K) & $0.196^{* * *}$ & & $0.272^{* * *}$ & & & \\
\hline Liquid Savings of $[100 \mathrm{~K}, 500 \mathrm{~K})$ & $0.206^{* * *}$ & & $0.313^{* * *}$ & & & \\
\hline Liquid Savings of $500 \mathrm{~K}$ or more & $0.278^{* * *}$ & & $0.419^{* * *}$ & & & \\
\hline Non-Housing Debt of $[1000,5000)$ & 0.094 & & & 0.076 & & \\
\hline Non-Housing Debt of [5K, 30K) & 0.052 & & & -0.022 & & \\
\hline Non-Housing Debt of $30 \mathrm{~K}$ or more & -0.008 & & & -0.052 & & \\
\hline Credit Score 680-719 & 0.058 & & & & 0.032 & \\
\hline Credit Score 720-760 & $0.156^{*}$ & & & & $0.228^{* * *}$ & \\
\hline Credit Score Above 760 & 0.085 & & & & $0.204^{* *}$ & \\
\hline Income in $(40 \mathrm{~K}, 75 \mathrm{~K}]$ & 0.042 & & & & & 0.088 \\
\hline Income in $(75 \mathrm{~K}, 150 \mathrm{~K}]$ & 0.111 & & & & & $0.172^{* *}$ \\
\hline Income greater than $150 \mathrm{~K}$ & $0.230^{* * *}$ & & & & & $0.342^{* * *}$ \\
\hline Demographic controls & $\checkmark$ & $\checkmark$ & $\checkmark$ & $\checkmark$ & $\checkmark$ & $\checkmark$ \\
\hline Expectation controls & $\checkmark$ & $\checkmark$ & $\checkmark$ & $\checkmark$ & $\checkmark$ & $\checkmark$ \\
\hline Adj. R2 & 0.65 & 0.64 & 0.65 & 0.63 & 0.64 & 0.64 \\
\hline Obs. & 790 & 790 & 790 & 790 & 790 & 790 \\
\hline Mean(dep. var.) & 11.847 & 11.847 & 11.847 & 11.847 & 11.847 & 11.847 \\
\hline \multicolumn{7}{|l|}{ B. $\log (\mathrm{WTP})-\log (\mathrm{Appr})}$. \\
\hline Interest Rate Low & 0.056 & 0.048 & 0.046 & 0.045 & 0.044 & 0.042 \\
\hline Equity in $(0,50 \mathrm{~K}]$ & 0.087 & 0.122 & & & & \\
\hline Equity in $(50,125 \mathrm{~K}]$ & $0.208^{*}$ & $0.293^{* * *}$ & & & & \\
\hline Equity in $(125 \mathrm{~K}, 200 \mathrm{~K}]$ & 0.133 & $0.244^{* *}$ & & & & \\
\hline Equity of more than $200 \mathrm{~K}$ & 0.056 & 0.185 & & & & \\
\hline Liquid Savings of [5K, 30K) & -0.020 & & 0.013 & & & \\
\hline Liquid Savings of $[30 \mathrm{~K}, 100 \mathrm{~K})$ & $0.135^{*}$ & & $0.187^{* * *}$ & & & \\
\hline Liquid Savings of [100K, 500K) & $0.161^{* *}$ & & $0.214^{* * *}$ & & & \\
\hline Liquid Savings of $500 \mathrm{~K}$ or more & $0.233^{* * *}$ & & $0.281^{* * *}$ & & & \\
\hline Non-Housing Debt of $[1000,5000)$ & 0.103 & & & 0.091 & & \\
\hline Non-Housing Debt of $[5 \mathrm{~K}, 30 \mathrm{~K})$ & 0.032 & & & -0.016 & & \\
\hline Non-Housing Debt of $30 \mathrm{~K}$ or more & 0.008 & & & -0.032 & & \\
\hline Credit Score 680-719 & -0.006 & & & & -0.008 & \\
\hline Credit Score 720-760 & 0.131 & & & & $0.189^{* *}$ & \\
\hline Credit Score Above 760 & 0.074 & & & & $0.157^{*}$ & \\
\hline Income in $(40 \mathrm{~K}, 75 \mathrm{~K}]$ & -0.020 & & & & & 0.034 \\
\hline Income in $(75 \mathrm{~K}, 150 \mathrm{~K}]$ & -0.009 & & & & & 0.073 \\
\hline Income greater than $150 \mathrm{~K}$ & 0.047 & & & & & $0.179^{* *}$ \\
\hline Demographic controls & $\checkmark$ & $\checkmark$ & $\checkmark$ & $\checkmark$ & $\checkmark$ & $\checkmark$ \\
\hline Expectation controls & $\checkmark$ & $\checkmark$ & $\checkmark$ & $\checkmark$ & $\checkmark$ & $\checkmark$ \\
\hline Adj. R2 & 0.15 & 0.14 & 0.15 & 0.14 & 0.15 & 0.14 \\
\hline Obs. & 790 & 790 & 790 & 790 & 790 & 790 \\
\hline Mean(dep. var.) & -0.305 & -0.305 & -0.305 & -0.305 & -0.305 & -0.305 \\
\hline
\end{tabular}


Table A-2: Robustness to different samples and weighting. Table shows the main average effects reported in Figures 2, 3 and 5 of the main text under different weighting or sample selection schemes. Part (a) reproduces the results from the main text, for reference. In part (b), sample weights are used. In part (c), we do not drop respondents based on self-appraised home value, age, or response time. In part (d), we restrict the sample to respondents who state a probability of moving over the next 3 years of $20 \%$ or higher and a probability of buying conditional on moving of $50 \%$ or higher. Sample sizes (before trimming) - parts (a) and (b): 962 (698 owners, 264 renters); part (c): 1139 (820 owners, 319 renters); part (d): 385 (259 owners, 126 renters).

\begin{tabular}{|c|c|c|c|c|c|c|}
\hline & \multicolumn{6}{|c|}{ Trimmed means without top/bottom X\% } \\
\hline & \multicolumn{3}{|c|}{$X=2.5$} & \multicolumn{3}{|c|}{$X=5$} \\
\hline & Full & Owner & Renter & Full & Owner & Renter \\
\hline \multicolumn{7}{|l|}{ (a) As in main text (for reference) } \\
\hline $\log ($ WTP with DP $\geq 5 \%)-\log ($ WTP with $\mathrm{DP}=20 \%)$ & 0.185 & 0.093 & 0.462 & 0.152 & 0.064 & 0.395 \\
\hline $\log ($ WTP with $r=6.5 \%)-\log ($ WTP with $r=4.5 \%)$ & -0.049 & -0.046 & -0.048 & -0.044 & -0.042 & -0.046 \\
\hline $\log (\mathrm{WTP}$ with $100 \mathrm{k}$ windfall $)-\log \left(\mathrm{WTP}_{\mathrm{Q} 3}\right)$ & 0.135 & 0.085 & 0.267 & 0.109 & 0.070 & 0.249 \\
\hline \multicolumn{7}{|l|}{ (b) Weighted } \\
\hline $\log ($ WTP with DP $\geq 5 \%)-\log ($ WTP with $\mathrm{DP}=20 \%)$ & 0.206 & 0.107 & 0.506 & 0.161 & 0.075 & 0.388 \\
\hline $\log ($ WTP with $r=6.5 \%)-\log ($ WTP with $r=4.5 \%)$ & -0.049 & -0.046 & -0.065 & -0.044 & -0.043 & -0.052 \\
\hline $\log (\mathrm{WTP}$ with $100 \mathrm{k}$ windfall $)-\log \left(\mathrm{WTP}_{\mathrm{Q3}}\right)$ & 0.145 & 0.092 & 0.231 & 0.117 & 0.079 & 0.233 \\
\hline \multicolumn{7}{|l|}{ (c) No drops based on appraisal, age, response time } \\
\hline $\log ($ WTP with $\mathrm{DP} \geq 5 \%)-\log ($ WTP with $\mathrm{DP}=20 \%)$ & 0.175 & 0.089 & 0.419 & 0.140 & 0.063 & 0.364 \\
\hline $\log ($ WTP with $r=6.5 \%)-\log ($ WTP with $r=4.5 \%)$ & -0.043 & -0.042 & -0.033 & -0.041 & -0.039 & -0.032 \\
\hline $\log (\mathrm{WTP}$ with $100 \mathrm{k}$ windfall $)-\log \left(\mathrm{WTP}_{\mathrm{Q3}}\right)$ & 0.124 & 0.077 & 0.247 & 0.101 & 0.064 & 0.232 \\
\hline \multicolumn{7}{|c|}{ (d) Only respondents with $\operatorname{Pr}($ move over next 3 years $) \geq 20 \%$ and $\operatorname{Pr}($ buy $\mid$ move $) \geq 50 \%$} \\
\hline $\log ($ WTP with $\mathrm{DP} \geq 5 \%)-\log (\mathrm{WTP}$ with $\mathrm{DP}=20 \%)$ & 0.180 & 0.069 & 0.437 & 0.158 & 0.060 & 0.401 \\
\hline $\log ($ WTP with $r=6.5 \%)-\log ($ WTP with $r=4.5 \%)$ & -0.054 & -0.049 & -0.073 & -0.051 & -0.046 & -0.065 \\
\hline $\log (\mathrm{WTP}$ with $100 \mathrm{k}$ windfall $)-\log \left(\mathrm{WTP}_{\mathrm{Q} 3}\right)$ & 0.118 & 0.083 & 0.196 & 0.097 & 0.071 & 0.178 \\
\hline
\end{tabular}


Table A-3: Heterogeneity in down payment fractions in Q2 among current owners. Coefficient estimates from OLS regressions; dependent variable: down payment as fraction of WTP in Q2. Significance (based on robust standard errors): ${ }^{*} p<0.1,{ }^{* *} p<0.05,{ }^{* * *} p<0.01$.

\begin{tabular}{|c|c|c|c|c|c|c|}
\hline Interest Rate Low & $-4.15^{* *}$ & $-3.32^{*}$ & $-3.34^{*}$ & $-3.38^{*}$ & -3.11 & $-4.07^{* *}$ \\
\hline Age & $0.45^{* * *}$ & $0.66^{* * *}$ & $0.76^{* * *}$ & $0.80^{* * *}$ & $0.83^{* * *}$ & $0.37^{* * *}$ \\
\hline Number correct on numeracy test & $2.85^{* * *}$ & $3.60^{* * *}$ & $4.00^{* * *}$ & $3.55^{* * *}$ & $4.25^{* * *}$ & $3.14^{* * *}$ \\
\hline Education: College Degree or higher & -2.32 & -0.86 & 1.11 & 0.70 & 2.14 & -1.93 \\
\hline Married & 0.90 & 2.45 & $4.78^{* *}$ & 3.15 & $5.41^{* *}$ & $3.96^{*}$ \\
\hline Male & -0.62 & -0.66 & -1.32 & -1.02 & -0.73 & -1.24 \\
\hline Risk Averse & -0.70 & 2.43 & 0.49 & 0.50 & 0.31 & -0.62 \\
\hline Risk Loving & 2.91 & $5.52^{*}$ & $6.36^{* *}$ & $6.77^{* *}$ & $5.90^{*}$ & 3.73 \\
\hline $\mathrm{E}(\mathrm{HP}$ growth, $1 \mathrm{yr})$ & -0.10 & -0.03 & -0.03 & -0.08 & -0.09 & -0.01 \\
\hline $\operatorname{Pr}($ move over next 3 yrs) & 0.03 & 0.01 & 0.01 & 0.00 & 0.00 & 0.03 \\
\hline $\operatorname{Pr}$ (buy $\mid$ move) & $0.11^{* * *}$ & $0.15^{* * *}$ & $0.15^{* * *}$ & $0.14^{* * *}$ & $0.17^{* * *}$ & $0.10^{* *}$ \\
\hline Equity in $(0,50 \mathrm{~K}]$ & $3.44^{*}$ & & & & & 3.41 \\
\hline Equity in $(50,125 \mathrm{~K}]$ & $11.27^{* * *}$ & & & & & $10.69^{* * *}$ \\
\hline Equity in $(125 \mathrm{~K}, 200 \mathrm{~K}]$ & $25.28^{* * *}$ & & & & & $23.78^{* * *}$ \\
\hline Equity of more than $200 \mathrm{~K}$ & $32.79^{* * *}$ & & & & & $30.79^{* * *}$ \\
\hline Liquid Savings of $[5 \mathrm{~K}, 30 \mathrm{~K})$ & & -2.65 & & & & $-6.15^{* *}$ \\
\hline Liquid Savings of $[30 \mathrm{~K}, 100 \mathrm{~K})$ & & 0.33 & & & & $-5.43^{*}$ \\
\hline Liquid Savings of $[100 \mathrm{~K}, 500 \mathrm{~K})$ & & $11.50^{* * *}$ & & & & 1.95 \\
\hline Liquid Savings of $500 \mathrm{~K}$ or more & & $14.55^{* * *}$ & & & & 0.85 \\
\hline Non-Housing Debt of $[1000,5000)$ & & & $-6.29 *$ & & & -2.72 \\
\hline Non-Housing Debt of [5K, 30K) & & & $-12.38^{* * *}$ & & & $-6.59^{* *}$ \\
\hline Non-Housing Debt of $30 \mathrm{~K}$ or more & & & $-12.25^{* * *}$ & & & $-5.85^{* *}$ \\
\hline Credit Score 680-719 & & & & 0.01 & & -2.95 \\
\hline Credit Score 720-760 & & & & 4.90 & & 2.24 \\
\hline Credit Score Above 760 & & & & $9.73^{* * *}$ & & 3.53 \\
\hline Income in $(40 \mathrm{~K}, 75 \mathrm{~K}]$ & & & & & -4.06 & -4.20 \\
\hline Income in $(75 \mathrm{~K}, 150 \mathrm{~K}]$ & & & & & -5.88 & $-7.51^{* *}$ \\
\hline Income greater than $150 \mathrm{~K}$ & & & & & -2.36 & $-11.92^{* * *}$ \\
\hline Constant & $-27.65^{* * *}$ & $-38.83^{* * *}$ & $-36.71^{* * *}$ & $-48.77^{* * *}$ & $-47.97^{* * *}$ & $-15.32 *$ \\
\hline Region \& home type controls & $\checkmark$ & $\checkmark$ & $\checkmark$ & $\checkmark$ & $\checkmark$ & $\checkmark$ \\
\hline Adj. R2 & 0.32 & 0.22 & 0.21 & 0.19 & 0.18 & 0.34 \\
\hline Obs. & 599 & 599 & 599 & 599 & 599 & 599 \\
\hline Mean(dep. var.) & 26.37 & 26.37 & 26.37 & 26.37 & 26.37 & 26.37 \\
\hline
\end{tabular}


Table A-4: Heterogeneity in the effect of the lower down payment requirement on WTP among current owners. Coefficient estimates from OLS regressions; dependent variable: $\log \left(\mathrm{WTP}_{\mathrm{Q} 2}\right)-\log \left(\mathrm{WTP}_{\mathrm{Q} 1}\right)$. Significance (based on robust standard errors): ${ }^{*} p<0.1,{ }^{* *} p<0.05$, *** $p<0.01$.

\begin{tabular}{|c|c|c|c|c|c|c|}
\hline Interest Rate Low & -0.020 & -0.016 & -0.016 & -0.011 & -0.015 & -0.014 \\
\hline Age & -0.001 & -0.002 & $-0.002^{* *}$ & $-0.002^{*}$ & $-0.002^{* * *}$ & -0.001 \\
\hline Number correct on numeracy test & $-0.036^{* *}$ & $-0.030^{*}$ & $-0.034^{* *}$ & $-0.030^{* *}$ & $-0.032^{* *}$ & $-0.033^{* *}$ \\
\hline Education: College Degree or higher & -0.032 & -0.023 & -0.034 & -0.027 & -0.023 & -0.021 \\
\hline Married & 0.043 & 0.035 & 0.027 & 0.035 & 0.042 & 0.056 \\
\hline Male & 0.020 & 0.021 & 0.021 & 0.026 & 0.022 & 0.026 \\
\hline Risk Averse & 0.007 & -0.008 & -0.000 & 0.006 & -0.003 & 0.005 \\
\hline Risk Loving & -0.008 & -0.022 & -0.023 & -0.025 & -0.018 & -0.009 \\
\hline $\mathrm{E}(\mathrm{HP}$ growth, 1 yr) & -0.002 & -0.003 & -0.002 & -0.003 & -0.002 & -0.003 \\
\hline $\operatorname{Pr}($ move over next 3 yrs $)$ & -0.000 & -0.000 & 0.000 & -0.000 & 0.000 & -0.000 \\
\hline $\operatorname{Pr}($ buy $\mid$ move $)$ & 0.000 & 0.000 & -0.000 & 0.000 & -0.000 & 0.000 \\
\hline Equity in $(0,50 \mathrm{~K}]$ & -0.103 & & & & & -0.068 \\
\hline Equity in $(50,125 \mathrm{~K}]$ & $-0.226^{* * *}$ & & & & & $-0.182^{* * *}$ \\
\hline Equity in $(125 \mathrm{~K}, 200 \mathrm{~K}]$ & $-0.177^{* *}$ & & & & & -0.125 \\
\hline Equity of more than $200 \mathrm{~K}$ & $-0.175^{* *}$ & & & & & -0.127 \\
\hline Liquid Savings of $[5 \mathrm{~K}, 30 \mathrm{~K})$ & & -0.006 & & & & 0.022 \\
\hline Liquid Savings of [30K, 100K] & & -0.037 & & & & 0.001 \\
\hline Liquid Savings of [100K, 500K) & & $-0.068^{*}$ & & & & -0.015 \\
\hline Liquid Savings of $500 \mathrm{~K}$ or more & & -0.055 & & & & -0.011 \\
\hline Non-Housing Debt of $[1000,5000)$ & & & -0.007 & & & -0.006 \\
\hline Non-Housing Debt of [5K, 30K) & & & -0.002 & & & -0.016 \\
\hline Non-Housing Debt of $30 \mathrm{~K}$ or more & & & 0.010 & & & 0.002 \\
\hline Credit Score 680-719 & & & & $-0.135^{*}$ & & $-0.131^{*}$ \\
\hline Credit Score 720-760 & & & & $-0.173^{* * *}$ & & $-0.147^{* *}$ \\
\hline Credit Score Above 760 & & & & $-0.127^{*}$ & & -0.087 \\
\hline Income in $(40 \mathrm{~K}, 75 \mathrm{~K}]$ & & & & & -0.023 & -0.012 \\
\hline Income in $(75 \mathrm{~K}, 150 \mathrm{~K}]$ & & & & & -0.026 & -0.013 \\
\hline Income greater than $150 \mathrm{~K}$ & & & & & $-0.075^{*}$ & -0.053 \\
\hline Constant & $0.458^{* * *}$ & $0.326^{* * *}$ & $0.362^{* * *}$ & $0.442^{* * *}$ & $0.365^{* * *}$ & $0.498^{* * *}$ \\
\hline Region \& home type controls & $\checkmark$ & $\checkmark$ & $\checkmark$ & $\checkmark$ & $\checkmark$ & $\checkmark$ \\
\hline Adj. R2 & 0.04 & 0.00 & -0.00 & 0.02 & 0.00 & 0.03 \\
\hline Obs. & 599 & 599 & 599 & 599 & 599 & 599 \\
\hline Mean(dep. var.) & 0.092 & 0.092 & 0.092 & 0.092 & 0.092 & 0.092 \\
\hline
\end{tabular}


Table A-5: Heterogeneity in the effect of $\$ \mathbf{1 0 0 , 0 0 0}$ wealth shock on WTP among current owners. Coefficient estimates from OLS regressions; dependent variable: $\log \left(\mathrm{WTP}_{\mathrm{Q}_{4}}\right)-\log \left(\mathrm{WTP}_{\mathrm{Q3}_{3}}\right)$. Significance (based on robust standard errors): ${ }^{*} p<0.1,{ }^{* *} p<0.05,{ }^{* * *} p<0.01$.

\begin{tabular}{|c|c|c|c|c|c|c|}
\hline Interest Rate Low & -0.002 & 0.000 & 0.000 & -0.001 & -0.000 & -0.002 \\
\hline Age & -0.001 & $-0.001^{*}$ & $-0.002^{* * *}$ & $-0.001^{* *}$ & $-0.002^{* * *}$ & -0.001 \\
\hline Number correct on numeracy test & 0.003 & 0.004 & 0.001 & 0.003 & 0.002 & 0.009 \\
\hline Education: College Degree or higher & -0.019 & -0.019 & -0.028 & -0.022 & -0.015 & -0.009 \\
\hline Married & $-0.079^{* * *}$ & $-0.079^{* * *}$ & $-0.087^{* * *}$ & $-0.082^{* * *}$ & $-0.065^{* * *}$ & $-0.060^{* *}$ \\
\hline Male & 0.024 & 0.025 & 0.026 & 0.026 & 0.025 & 0.025 \\
\hline Risk Averse & 0.002 & -0.005 & -0.000 & 0.004 & -0.004 & -0.001 \\
\hline Risk Loving & 0.023 & 0.018 & 0.016 & 0.015 & 0.021 & 0.024 \\
\hline $\mathrm{E}(\mathrm{HP}$ growth, $1 \mathrm{yr})$ & $0.004^{*}$ & 0.004 & $0.004^{*}$ & 0.004 & $0.004^{*}$ & $0.004^{*}$ \\
\hline $\operatorname{Pr}($ move over next 3 yrs $)$ & -0.000 & -0.000 & 0.000 & -0.000 & 0.000 & -0.000 \\
\hline $\operatorname{Pr}($ buy $\mid$ move $)$ & $-0.001^{* *}$ & $-0.001^{* *}$ & $-0.001^{* *}$ & $-0.001^{* *}$ & $-0.001^{* *}$ & $-0.001^{*}$ \\
\hline Equity in $(0,50 \mathrm{~K}]$ & 0.008 & & & & & 0.032 \\
\hline Equity in $(50,125 \mathrm{~K}]$ & -0.018 & & & & & 0.015 \\
\hline Equity in $(125 \mathrm{~K}, 200 \mathrm{~K}]$ & -0.048 & & & & & -0.015 \\
\hline Equity of more than $200 \mathrm{~K}$ & -0.048 & & & & & -0.009 \\
\hline Liquid Savings of $[5 K, 30 K)$ & & -0.033 & & & & -0.029 \\
\hline Liquid Savings of $[30 \mathrm{~K}, 100 \mathrm{~K})$ & & -0.032 & & & & -0.014 \\
\hline Liquid Savings of [100K, $500 \mathrm{~K})$ & & $-0.058^{* *}$ & & & & -0.032 \\
\hline Liquid Savings of $500 \mathrm{~K}$ or more & & $-0.050^{* *}$ & & & & -0.022 \\
\hline Non-Housing Debt of $[1000,5000)$ & & & -0.005 & & & -0.018 \\
\hline Non-Housing Debt of [5K, 30K) & & & -0.007 & & & -0.025 \\
\hline Non-Housing Debt of $30 \mathrm{~K}$ or more & & & 0.024 & & & 0.010 \\
\hline Credit Score 680-719 & & & & -0.045 & & -0.045 \\
\hline Credit Score 720-760 & & & & -0.053 & & -0.041 \\
\hline Credit Score Above 760 & & & & -0.059 & & -0.041 \\
\hline Income in $(40 \mathrm{~K}, 75 \mathrm{~K}]$ & & & & & -0.040 & -0.041 \\
\hline Income in $(75 \mathrm{~K}, 150 \mathrm{~K}]$ & & & & & -0.054 & -0.055 \\
\hline Income greater than $150 \mathrm{~K}$ & & & & & $-0.079^{* *}$ & $-0.071^{*}$ \\
\hline Constant & $0.220^{* * *}$ & $0.245^{* * *}$ & $0.257^{* * *}$ & $0.285^{* * *}$ & $0.283^{* * *}$ & $0.245^{* * *}$ \\
\hline Region \& home type controls & $\checkmark$ & $\checkmark$ & $\checkmark$ & $\checkmark$ & $\checkmark$ & $\checkmark$ \\
\hline Adj. R2 & 0.07 & 0.06 & 0.06 & 0.07 & 0.07 & 0.07 \\
\hline Obs. & 599 & 599 & 599 & 599 & 599 & 599 \\
\hline Mean(dep. var.) & 0.084 & 0.084 & 0.084 & 0.084 & 0.084 & 0.084 \\
\hline
\end{tabular}

